\title{
Influence of hydrogen implantation on emission from the silicon vacancy in $4 \mathrm{H}-\mathrm{SiC}$
}

\author{
M. E. Bathen, ${ }^{1, \text { a) }}$ A. Galeckas, ${ }^{1}$ J. Coutinho, ${ }^{2}$ and L. Vines ${ }^{1}$ \\ ${ }^{1)}$ Department of Physics/ Centre for Materials Science and Nanotechnology, University of Oslo, N-0316 Oslo, \\ Norway \\ ${ }^{2)}$ Department of Physics and I3N, University of Aveiro, Campus Santiago, 3810-193 Aveiro, \\ Portugal
}

(Dated: 20 January 2020)

The silicon vacancy $\left(V_{\mathrm{Si}}\right)$ in $4 \mathrm{H}-\mathrm{SiC}$ is a room temperature single-photon emitter with a controllable high-spin ground state, and is a promising candidate for future quantum technologies. However, controlled defect formation remains a challenge, and recently it was shown that common formation methods such as proton irradiation may in fact lower the intensity of photoluminescence (PL) emission from $V_{\mathrm{Si}}$ as compared to other ion species. Herein, we combine hybrid density functional calculations and PL studies of proton-irradiated n-type 4H-SiC material to explore the energetics and stability of hydrogen-related defects, situated both interstitially and in defect complexes with $V_{\mathrm{Si}}$, and confirm the stability of hydrogen in different interstitial and substitutional configurations. Indeed, $V_{\mathrm{Si}^{-}}-\mathrm{H}$ is energetically favorable if $V_{\mathrm{Si}}$ is already present in the material, e.g., following irradiation or ion implantation. We demonstrate that hydrogen has a significant impact on electrical and optical properties of $V_{\mathrm{Si}}$, by altering the charge states suitable for quantum technology applications, and provide an estimate for the shift in thermodynamic transition levels. Furthermore, by correlating the theoretical predictions with PL measurements of $4 \mathrm{H}-\mathrm{SiC}$ samples irradiated by protons at high $\left(400{ }^{\circ} \mathrm{C}\right)$ and room temperatures, we associate the observed quenching of $V_{\mathrm{Si}}$ emission in the case of high-temperature and highfluence proton irradiation with the increased mobility of $\mathrm{H}_{i}$, which may initiate $V_{\mathrm{Si}}-\mathrm{H}$ complex formation at temperatures above $400{ }^{\circ} \mathrm{C}$. The important implication of hydrogen being present is that it obstructs formation of reliable and efficient single-photon emitters based on silicon vacancy defects in $4 \mathrm{H}-\mathrm{SiC}$.

\section{INTRODUCTION}

Solid-state single-photon emitters and controllable spin centers are currently in high demand for applications within quantum computing, communication, imaging and sensing. Silicon carbide, and the $4 \mathrm{H}$ polytype due to its mature material processing and fabrication in particular, is a promising host for qubit defects. $4 \mathrm{H}-\mathrm{SiC}$ harbors several candidate defects exhibiting desirable properties such as single-photon emission in the near-infrared and stable and controllable spin states, even at room temperature [1,2]. However, although isolated point defects can be detected and identified in $4 \mathrm{H}-\mathrm{SiC}$, both controlled formation and fully reliable detection of the defects remain a challenge.

Promising qubit contenders in $4 \mathrm{H}-\mathrm{SiC}$ include the silicon vacancy $\left(V_{\mathrm{Si}}\right)[3]$, the silicon-carbon divacancy $\left(V_{\mathrm{Si}} V_{\mathrm{C}}\right)[4]$, the carbon antisite-vacancy pair $\left(\mathrm{C}_{\mathrm{Si}} V_{\mathrm{C}}\right)$ [5] and the nitrogenvacancy center $\left(\mathrm{N}_{\mathrm{C}} V_{\mathrm{Si}}\right)$ [6]. The high fraction of $V_{\mathrm{Si}}$ emission directed into the zero-phonon line (ZPL) [7], along with the higher stability of $V_{\mathrm{Si}}$ emission energies towards stray electric fields [8-10] and device fabrication [11] as compared to the complexes, mark the silicon vacancy as a frontrunner for quantum technology applications.

$V_{\mathrm{Si}}$ can inhabit two different lattice sites in $4 \mathrm{H}-\mathrm{SiC}$, the hexagonal $(h)$ and pseudo-cubic $(k)$, and therefore exists in two configurations. Accordingly, photoluminescence (PL) spectra from n-type $4 \mathrm{H}-\mathrm{SiC}$ typically showcase two ZPLs related to $V_{\mathrm{Si}}: \mathrm{V} 1$ at $1.438 \mathrm{eV}$ assigned to the negative $V_{\mathrm{Si}}$ at a

a)Electronic mail: m.e.bathen@fys.uio.no hexagonal lattice site, $V_{\mathrm{Si}}^{-}(h)$, and $\mathrm{V} 2$ at $1.352 \mathrm{eV}$ attributed to $V_{\mathrm{Si}}^{-}(k)[8,12]$. Despite the promising properties of $V_{\mathrm{Si}}$, emission from $V_{\mathrm{Si}}$ remains low, and is commonly enhanced by nanostructuring of the $4 \mathrm{H}-\mathrm{SiC}$ surface to form waveguides for single-defect spectroscopy $[13,14]$. Furthermore, only the negative charge state of $V_{\mathrm{Si}}$ manifests single-photon emission and millisecond spin coherence times [13]. Recently, the 2- and 3- charge states were shown to be more stable than $V_{\mathrm{Si}}^{-}$in n-type material, by correlating density functional theory (DFT) calculations to deep level transient spectroscopy (DLTS) measurements [9]. Indeed, substantial enhancement of emission from $V_{\mathrm{Si}}$ ensembles [9] and control of the charge state of isolated $V_{\mathrm{Si}}$ defects [15] was recently demonstrated via application of electric fields, and attributed to selective population of the bright and dark charge states.

In contrast to the carbon vacancy, which is commonly present even in state-of-the-art epitaxial $4 \mathrm{H}-\mathrm{SiC}$ material [16], the silicon vacancy is challenging to form thermally. With a formation energy of $\sim 7.5 \mathrm{eV}$ in the neutral charge state [1,9], which is predominant under the intrinsic conditions that manifest at high temperatures, only approximately $10^{7} \mathrm{~cm}^{-3}$ of silicon vacancies can be formed by annealing $4 \mathrm{H}-\mathrm{SiC}$ at $2000^{\circ} \mathrm{C}$. Accordingly, irradiation and ion implantation are the methods of choice for silicon vacancy formation. Unfortunately, the placement of isolated defects during an irradiation procedure is inherently randomized, but proton beam writing [17] or irradiation through nano-scale apertures [18] enhance the reproducibility when single defects are desired. To successfully employ silicon vacancies as efficient single-photon sources for quantum cryptography or reliable multi-level single spins for quantum computing, comprehensive investigations into the effects of processing conditions on $V_{\mathrm{Si}}$ formation 
and emission are needed.

Recently, it was shown that $V_{\mathrm{Si}}$-related PL is substantially weaker when the silicon vacancies are formed by hydrogen implantation compared to that of, e.g., helium [18]. A possible explanation involves the implanted hydrogen atoms preferentially occupying $V_{\mathrm{Si}}$ sites, thereby altering the optoelectronic properties of the defect and effectively quenching the V1 and V2 emission lines. Helium, on the other hand, is inert, and may have a reduced impact on the $V_{\mathrm{Si}}$ emission. A theoretical study suggested that hydrogen is readily captured by silicon and carbon vacancies in $3 \mathrm{C}-\mathrm{SiC}$, while preferring the $V_{\mathrm{Si}}$ site over that of $V_{\mathrm{C}}$ [19]. However, vacancy-hydrogen complex formation is possible also in the $4 \mathrm{H}$ polytype, motivating for further investigation. Indeed, a deep-level defect at $0.73 \mathrm{eV}$ below the conduction band edge, observed by DLTS, was tentatively attributed to the $V_{\mathrm{Si}}-\mathrm{H}$ complex [20].

In the present work, we explore the impact of hydrogen on the formation and properties of $V_{\mathrm{Si}}$ in $4 \mathrm{H}-\mathrm{SiC}$ theoretically, by employing density functional calculations, and interpret our findings in light of photoluminescence measurements. We propose that the interstitial $\mathrm{H}$ configuration is lowest in energy, and that formation of the $V_{\mathrm{Si}^{-}}-\mathrm{H}$ complex is energetically favorable during, e.g., irradiation and subsequent heat treatments. Complex formation likely results in a quenching of $V_{\mathrm{Si}}$-related emission, and we propose hydrogen as an obstacle for efficient creation of reliable single-photon emitters using silicon vacancies in $4 \mathrm{H}-\mathrm{SiC}$. Moreover, we reaffirm that $\mathrm{H} \mathrm{mi-}$ grates substantially slower in n-type than p-type material, and find that $400-500{ }^{\circ} \mathrm{C}$ is likely sufficient for $\mathrm{H}$ to react with $V_{\mathrm{Si}}$ in n-type $4 \mathrm{H}-\mathrm{SiC}$. Finally, we study $V_{\mathrm{Si}}$-related emission experimentally in n-type $4 \mathrm{H}-\mathrm{SiC}$ samples, irradiated with protons to different fluences and at different temperatures, and attempt to explain our observations in light of the theoretical findings presented herein.

\section{METHODOLOGY}

\section{A. Theory}

Hydrogen-related defects in $4 \mathrm{H}-\mathrm{SiC}$ were studied using density functional theory as implemented in the Vienna $a b$ initio simulation package, or vASP, code [21-24]. The electronic ground state was obtained within the Kohn-Sham formalism, using the projector augmented-wave (PAW) method [25] and plane-waves to describe core and valence electrons, respectively. 400-atom hexagonal supercells were constructed from $5 \times 5 \times 2$ primitive cells along the main axes. The lattice constants used for $4 \mathrm{H}-\mathrm{SiC}$ were obtained using the PerdewBurke-Ernzerhof functional (PBE [26]), and PBE-level lattice parameters were chosen because PBE was mainly used when studying $\mathrm{H}$ diffusion.

Defect formation was accomplished by adding one hydrogen $(\mathrm{H})$ atom to form a hydrogen interstitial $\left(\mathrm{H}_{i}\right)$, and removing a $\mathrm{Si}$ atom to form a silicon vacancy $\left(V_{\mathrm{Si}}\right)$ or a $V_{\mathrm{Si}}-\mathrm{H}$ complex. The defect geometries were first optimized at the PBElevel by employing $2 \times 2 \times 2 \Gamma$-centered Brillouin-zone (BZ) sampling and relaxing until the maximum force was below
$0.01 \mathrm{eV} / \AA$. Starting from the resulting defect configuration, a $\Gamma$-only relaxation succeeded within screened hybrid density functional theory (HSE06 [27,28]) until maximum forces were below $0.05 \mathrm{eV} / \AA$. From these results, formation energy diagrams for all defects were constructed. The stopping criterion for the electronic self-consistent loop was set to $10^{-6} \mathrm{eV}$, and the plane-wave energy cut-off to $420 \mathrm{eV}$.

For the silicon monovacancy, the formation energies are based on calculations from Ref. [9], where we employed a 96-atom orthorombic supercell, the HSE06 functional and $2 \times 2 \times 2$ Monkhorst-Pack type BZ-sampling. Note that mirroring effects might influence the defect energetics for smaller supercells. However, the minimum distance between defects is $10 \AA$ for $V_{\mathrm{Si}}$ in the 96-atom supercell, and the calculated thermodynamic charge-state transition levels agree with those obtained for $V_{\mathrm{Si}}$ in tests with 400-atom supercells, and when comparing to experiment [9], within $\sim 0.1 \mathrm{eV}$. During migration, the defect strain field extends over a larger volume and particularly when a complex is involved. A larger 400atom supercell was therefore used to study migration of in terstitial hydrogen and formation of hydrogen-vacancy complexes herein. This method was previously successfully employed to study migration of the carbon vacancy $\left(V_{\mathrm{C}}\right)$ in $3 \mathrm{C}$ and $4 \mathrm{H}-\mathrm{SiC}$ [29], and excellent overlap between theory and experiment was found.

Electronic structure calculations employing the HSE06 functional appear to adequately capture the energetics of defects within $4 \mathrm{H}-\mathrm{SiC}$, as demonstrated in Refs. $[9,29]$ by combining DFT calculations with DLTS measurements for $V_{\mathrm{Si}}$ and $V_{\mathrm{C}}$, respectively. The band gap of the orthorombic supercell becomes $3.17 \mathrm{eV}$ when employing the $2 \times 2 \times 2 \mathrm{MP}$ k-mesh, which is close to the experimental value of $3.27 \mathrm{eV}$ [30]. The $\Gamma$-only HSE06 calculations employing hexagonal supercells yield a band gap of $3.48 \mathrm{eV}$. When discussing charge state transition levels herein, the calculated figures will refer to the valence band edge.

The formation energy of a semiconductor point defect is given by [31,32]

$$
\begin{aligned}
E^{\mathrm{f}}(q)=E_{\text {defect }}^{\text {total }}(q)-E_{\text {bulk }}^{\text {total }}- & \sum_{i} \Delta n_{i} \mu_{i} \\
& +q\left(\varepsilon_{\mathrm{VBM}}+\varepsilon_{\mathrm{F}}\right)+E^{\mathrm{FNV}} .
\end{aligned}
$$

Here, $E^{\text {total }}$ refers to the total energies of the defective and pristine supercells, $\Delta n_{i}$ is the number of atoms added (positive) or removed (negative), $\mu_{i}$ is the chemical potential for a particular species $(\mathrm{Si}, \mathrm{C}$ or $\mathrm{H}), \varepsilon_{\mathrm{VBM}}$ is the valence band maximum (VBM) and $\varepsilon_{\mathrm{F}}$ is the Fermi level position relative to VBM. Within this work, the chemical potentials were estimated by relaxations of bulk diamond, $\mathrm{Si}$ and hydrogen gas $\left(\mathrm{H}_{2}\right.$ in a periodic box) until all forces were below $0.005 \mathrm{eV} / \AA$. $E^{\mathrm{FNV}}$ is a correction term to account for the use of charged and finite-sized supercells, and we have employed the extended Freysoldt, Neugebauer and Van de Walle (FNV) correction scheme [33-35] herein.

From the formation energy diagrams of the different defects, we can estimate the binding energy of a corresponding 
complex, here exemplified by $V_{\mathrm{Si}}-\mathrm{H}$ :

$$
E^{\mathrm{b}}\left[\left(V_{\mathrm{Si}}-\mathrm{H}\right)^{3-}\right]=E^{\mathrm{f}}\left(V_{\mathrm{Si}}^{2-}\right)+E^{\mathrm{f}}\left(\mathrm{H}_{i}^{-}\right)-E^{\mathrm{f}}\left[\left(V_{\mathrm{Si}}-\mathrm{H}\right)^{3-}\right] .
$$

The binding energy depends on the charge state of the final defect complex, and thereby the Fermi level, and must be positive to ensure the stability of the complex in question. To obtain the complete dissociation energy needed to break up the complex, the migration barrier of the most mobile constituent (here $\mathrm{H}_{i}$ ) is added to $E^{\mathrm{b}}$.

Minimum energy paths (MEP) for defect migration were studied at the PBE-level using the climbing image nudged elastic band (CI-NEB) method [36,37], $\Gamma$-only BZ sampling, $420 \mathrm{eV}$ cut-off energy and between seven and eleven intermediate images. The forces were relaxed until the maximum force was below $0.01 \mathrm{eV} / \AA$ for all migration paths. NEB calculations require fixed initial and final geometries, and a chain of intermediate images are formed to provide an initial guess for the path of the migrating species. The images are connected via spring forces to keep them at a suitable distance, and are then collectively optimized, with the climbing image approach ensuring that the highest-energy image lands at the MEP maximum. Finally, the transition state electronic structure was refined by self-consistent field (SCF) calculations employing HSE06 for select migrational pathways.

Within the present work, we study seven different configurations of $\mathrm{H}_{i}$, and eight different migration paths involving axial and basal migration for two charge states $(+$ and -$)$. This is not exhaustive, as a fully comprehensive investigation into the nature of $\mathrm{H}_{i}$ in $4 \mathrm{H}-\mathrm{SiC}$ is outside the scope of this work. We leave a full qualitative summary of $\mathrm{H}_{i}$ to other works $[19,38,39]$, although one should note that semi-local functionals are employed and Ref. [19] concerns the 3C polytype. Instead, our aim is to determine if hydrogen is likely to alter the electronic structure and optical transitions of $V_{\mathrm{Si}}$ when both defects are present in $4 \mathrm{H}-\mathrm{SiC}$ material, and explore the likelihood of $V_{\mathrm{Si}}-\mathrm{H}$ complex formation. Therefore, to understand recent experimental findings, we focus on illuminating a representative behavior for $\mathrm{H}$ in $4 \mathrm{H}-\mathrm{SiC}$ and consider closely how hydrogen interacts with silicon vacancies. Higher-order complexes between $V_{\mathrm{Si}}$ and more than one $\mathrm{H}$ atom were not considered herein, but could contribute to the overall picture.

\section{B. Experiment}

Experimentally, we study PL emission from 4H-SiC samples that are proton-irradiated to different fluences and at different temperatures, to better understand the optimal formation conditions for $V_{\mathrm{Si}}$. $4 \mathrm{H}-\mathrm{SiC}$ samples holding $10 \mu \mathrm{m}$ epitaxial layers purchased from Cree, Inc were employed. The epi-layers were n-doped (nitrogen) with net carrier concentrations in the epi-layer of $1 \times 10^{15} \mathrm{~cm}^{-3}$, as determined by capacitance-voltage measurements. We study n-type $4 \mathrm{H}-\mathrm{SiC}$ samples implanted with $1.5 \mathrm{MeV}$ protons having a projected range of $\sim 20 \mu \mathrm{m}$, according to collision Monte Carlo calculations as manifested in the SRIM (Stopping and Range for Ions in Matter) code [40]. The samples were irradiated to fluences (a)
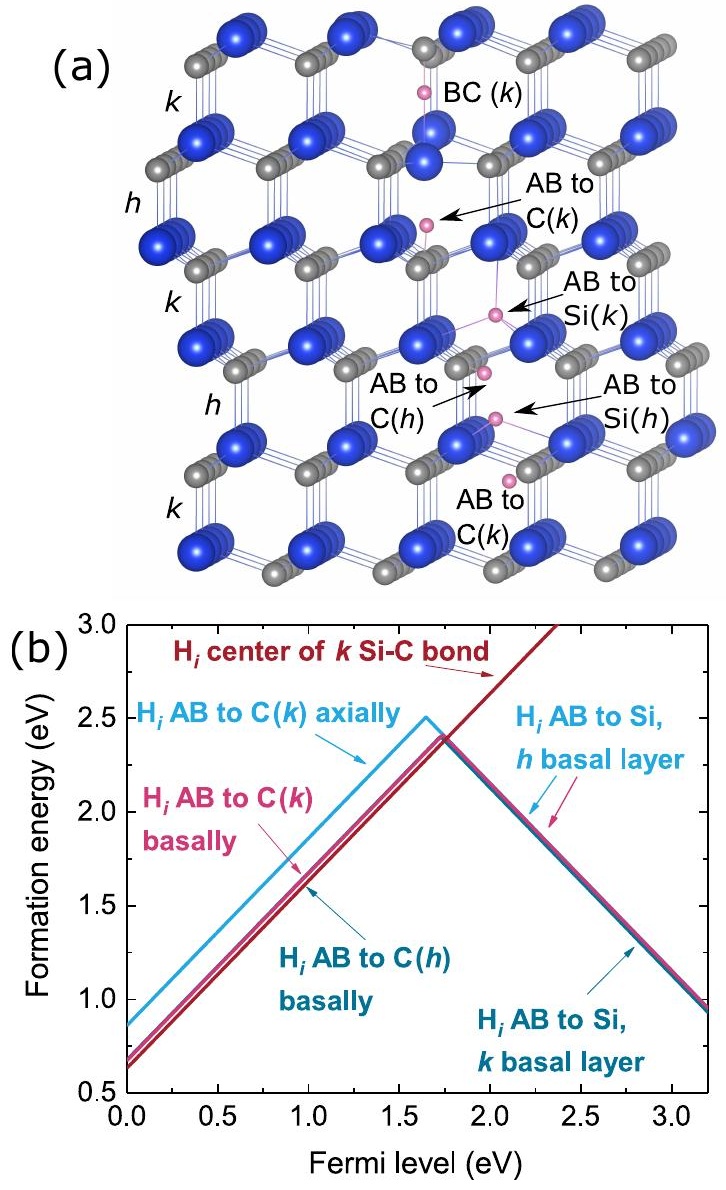

FIG. 1. (a) Favorable positions for $\mathrm{H}_{i}$ in the $4 \mathrm{H}-\mathrm{SiC}$ lattice, with the different lattice site configurations ( $h$ and $k$ ) highlighted to the left. Si atoms are shown in blue, $\mathrm{C}$ in gray and $\mathrm{H}$ in pink. The anti-bonding $(\mathrm{AB})$ to $\mathrm{C}$ and bond-centered $(\mathrm{BC})$ configurations reflect the positive charge state, while negative $\mathrm{H}$ is $\mathrm{AB}$ to $\mathrm{Si}$. (b) Formation energy diagrams for various configurations of $\mathrm{H}_{i}$. The energy of VBM is offset to zero.

of $1 \times 10^{13} \mathrm{~cm}^{-2}, 5 \times 10^{13} \mathrm{~cm}^{-2}$ and $1 \times 10^{14} \mathrm{~cm}^{-2}$, dubbed low, medium and high fluence, respectively. All implantations were performed with the samples tilted $\sim 8^{\circ}$ off with respect to the surface normal to reduce channeling, and at either room temperature (RT) or $400{ }^{\circ} \mathrm{C}$ (so-called hot implantation). Note that hot implantation is common in silicon carbide device processing, and is used to alleviate damage during implantation of dopants. Employing the dynamic annealing figure of $3 \%$ for $V_{\mathrm{Si}}$ estimated in Ref. [9], we arrive at $V_{\mathrm{Si}}$ concentrations in the $10^{16}-10^{17}$ range at the Bragg peak maximum.

Photoluminescence measurements were carried out at $10 \mathrm{~K}$ using a closed-cycle He refrigerator system (Janis, CCS450) and $675 \mathrm{~nm}$ wavelength $\mathrm{cw}$-laser of $1 \mathrm{~mW}$ power as an excitation source. The focused laser beam, impinging on the sample surface at $\sim 27$ degree angle, yielded an excitation intensity of $<100 \mathrm{Wcm}^{-2}$ and polarization perpendicular to the optical $c$ axis of $4 \mathrm{H}-\mathrm{SiC}$. PL signal was collected in a back-scattering geometry by a microscope objective (Mitutoya, LWD 10X), spectrally filtered (long-pass LP 750 filter) and analyzed by 
imaging spectrometer (Horiba, iHR320) coupled to EMCCD camera (Andor, LM658M) with a spectral resolution below $2 \mathrm{~nm}$.

As $4 \mathrm{H}-\mathrm{SiC}$ is virtually transparent to below-band gap illumination, the luminescence can be collected from the whole sample depth [9]. Consequently, in the experiments described herein we are probing both the proton irradiation tail and the Bragg peak of implanted hydrogen ions, and can collect luminescence deriving from defects located in either region. The V1 and V2 ZPLs are associated with the negative charge state of $h$ and $k V_{\mathrm{Si}}$, respectively [3,7], but no PL signal has (to the best of our knowledge) been attributed to complexes between $V_{\mathrm{Si}}$ and $\mathrm{H} . V_{\mathrm{Si}}$ requires high energies, and therefore irradiation, to form [1,29], and post-irradiation annealing is commonly performed to alleviate implantation damage and remove nonradiative channels. As this effect was something we wanted to probe herein, no post-irradiation annealing was performed.

\section{RESULTS}

\section{A. Theory}

\section{The hydrogen interstitial}

A selection of $\mathrm{H}_{i}$ configurations is presented in Figure 1, where 1(a) displays the preferred lattice sites with hexagonal and pseudo-cubic sites labeled as $h$ and $k$, respectively, and 1(b) contains formation energy diagrams for $\mathrm{H}_{i}$. We find that interstitial hydrogen is amphoteric in $4 \mathrm{H}-\mathrm{SiC}$, with a negative$U$ character for the $(+/-)$ transition near mid-gap. Upon altering the charge state, the $\mathrm{H}_{i}$ configuration also changes. The most stable configuration for $\mathrm{H}_{i}^{+}$is at (approximately) the center of a Si-C bond (bond-centered or $\mathrm{BC}$ ), in contrast to the finding of Ref. [38]. However, the antibonding (AB) state (to C) which is most stable in Ref. [38] lies less than $0.05 \mathrm{eV}$ higher in energy, and should be attainable at room

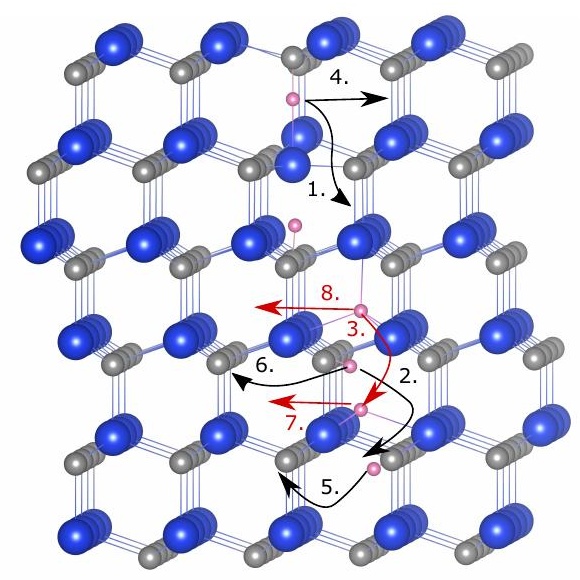

FIG. 2. Migration pathways for $\mathrm{H}_{i}$ in $4 \mathrm{H}-\mathrm{SiC}$. The jumps correspond to those of Table I. Black arrows designate migration of $\mathrm{H}_{i}^{+}$, and red arrows that of $\mathrm{H}_{i}^{-}$. temperature. Generally, $\mathrm{H}_{i}^{+}$attaches to a location with high electron density, i.e., either at the bond-centered site, or at the $\mathrm{AB}$ site to the $\mathrm{C}$ atom which is the anion species in $\mathrm{SiC}$. In n-type material, on the other hand, $\mathrm{H}_{i}^{-}$will dominate, preferring the $\mathrm{AB}$ to $\mathrm{Si}$ configuration. For both $V_{\mathrm{C}}$ [41] and $V_{\mathrm{Si}}$ [9], the $k$ site is more stable than the $h$ one in n-type material, by $\sim 0.1 \mathrm{eV}$. However, regarding sub-lattice site preference, no unified trend has been identified for $\mathrm{H}_{i}$ herein.

Interstitial hydrogen migration in $4 \mathrm{H}-\mathrm{SiC}$ was studied for eight different atomic hops (both axial and basal) using the CI-NEB method, the PBE functional and $\Gamma$-only k-point sampling. The migration pathways for various jumps of $\mathrm{H}_{i}$ are illustrated in Figure 2, with black arrows symbolizing $\mathrm{H}_{i}^{+}$and red arrows $\mathrm{H}_{i}^{-}$. Activation energies for the corresponding pathways of $\mathrm{H}_{i}$ in the + and - charge states, and explanations for the numbering in Figure 2, are summarized in Table I. The table contains migration barriers for $\mathrm{H}_{i}$ deduced from PBE-NEB, and select activation energies are refined by hybrid-SCF calculations. The charge state of $\mathrm{H}_{i}$ is found to significantly impact the migration barrier, with $E_{\mathrm{A}} \geq 0.5 \mathrm{eV}$ for both axial and basal migration of $\mathrm{H}_{i}^{+}$(at PBE-level), and $E_{\mathrm{A}} \geq 2.2 \mathrm{eV}$ for basal and $\geq 2.4 \mathrm{eV}$ for axial $\mathrm{H}_{i}^{-}$migration. This agrees with experiments, which have demonstrated that hydrogen migrates much faster in p-type than n-type material [42]. Moreover, the migration barriers found herein for $\mathrm{H}_{i}^{+}$ are very similar to those of Refs. [38,43], while the ones for $\mathrm{H}_{i}^{-}$are lower than the $\sim 3 \mathrm{eV}$ found in Ref. [38]. It is also interesting to note that like $V_{\mathrm{C}}$ [29], we find that the migration of interstitial $\mathrm{H}$ in $4 \mathrm{H}-\mathrm{SiC}$ is anisotropic, with $\mathrm{H}$ traveling faster along the basal directions than along the main crystalline axis. Assuming a jump frequency in the $10^{13} \mathrm{~s}^{-1}$ range, a migration barrier of $0.5 \mathrm{eV}$ translates into room temperature hydrogen motion, while a $\geq 2.2 \mathrm{eV}$ barrier prevents $\mathrm{H}$ diffusion (beyond $\sim 1 \mu \mathrm{m}$ ) below $500{ }^{\circ} \mathrm{C}$.

The charge state of $\mathrm{H}_{i}$ impacts not only the activation energy for diffusion, but also the form and nature of the pathway of motion. The minimum energy paths (MEPs) for $\mathrm{H}_{i}$ migration in $4 \mathrm{H}-\mathrm{SiC}$ are illustrated in Figure 3, with 3(a) and

TABLE I. Activation energies $\left(E_{\mathrm{A}}\right)$ for different axial and basal jumps of $\mathrm{H}_{i}^{+}$and $\mathrm{H}_{i}^{-}$in $4 \mathrm{H}-\mathrm{SiC}$ (see Figure 1 for the notation, and Figure 2 for illustrations of the migration paths). The PBE and HSE data columns refer to the two steps of the calculation, namely (1) the climbing image NEB run and (2) the SCF calculation to refine the transition state within HSE06. All activation energies for individual jumps are calculated with respect to the energy of the initial state.

\begin{tabular}{lcccr}
\hline \hline Jump & \multicolumn{4}{c}{ Activation energy, $E_{\mathrm{A}}(\mathrm{eV})$} \\
\hline Charge state & \multicolumn{2}{c}{$q=+1$} & \multicolumn{2}{c}{$q=-1$} \\
Functional & PBE & HSE & PBE & HSE \\
\hline 1. Axial $\mathrm{BC}(k) \rightarrow \mathrm{BC}(h)$ & 0.49 & 0.61 & & \\
2. Axial $\mathrm{AB} \mathrm{C}(h) \rightarrow \mathrm{C}(k)$ & 0.65 & & & \\
3. Axial $\mathrm{AB} \mathrm{Si}(k) \rightarrow \mathrm{Si}(h)$ & & & 2.36 & 2.67 \\
\hline 4. Basal $\mathrm{BC}(k)$ & 0.51 & & & \\
5. Basal AB to C $(k)$ & 0.51 & & & \\
6. Basal $\mathrm{AB}$ to $\mathrm{C}(h)$ & 0.50 & 0.45 & & \\
7. Basal $\mathrm{AB}$ to $\mathrm{Si}(h)$ & & & 2.19 & 2.28 \\
8. Basal $\mathrm{AB}$ to $\mathrm{Si}(k)$ & & & 2.62 & \\
\hline \hline
\end{tabular}



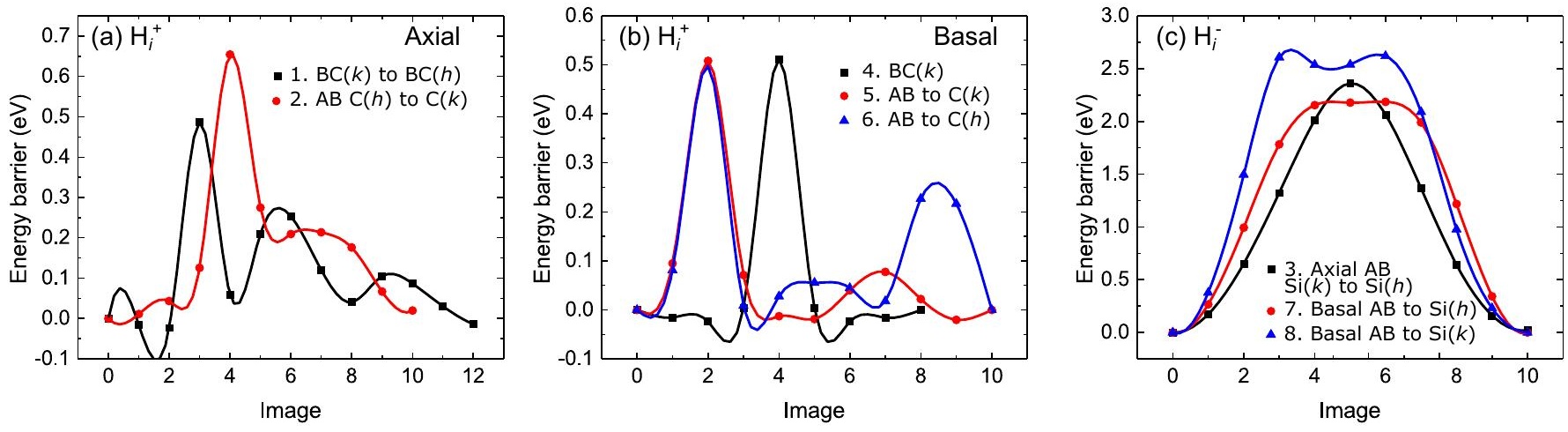

FIG. 3. Potential energy surfaces for migration of $\mathrm{H}_{i}$ in $4 \mathrm{H}-\mathrm{SiC}$. The migration paths are as outlined in Figure 2, and are calculated using the CI-NEB method at the PBE-level. Panel (a) shows the minimum energy path (MEP) for $\mathrm{H}_{i}^{+}$migrating axially and (b) for $\mathrm{H}_{i}^{+}$moving basally, while (c) depicts basal and axial migration of $\mathrm{H}_{i}^{-}$. The solid lines are cubic-spline interpolations of the data obtained from $\mathrm{CI}-\mathrm{NEB}$ calculations, and are intended as eye-guides.

3(b) showcasing the potential energy surfaces for $\mathrm{H}_{i}^{+}$migrating axially and basally, respectively, while 3(c) contains the MEPs for axial and basal $\mathrm{H}_{i}^{-}$jumps. The pathways are identified with numbers in the legends, corresponding to those in Table I. $\mathrm{H}_{i}^{+}$prefers to reside either at a bond center or in an antibonding configuration to a $\mathrm{C}$ atom, which is accompanied by MEPs with several intermediate transition states and local minima (Figs. 3a and 3b). The oscillations largely correspond to rotations of the $\mathrm{C}-\mathrm{H}$ bonds, while the highest-lying transition state structures are often similar to the ground-state configurations of $\mathrm{H}_{i}^{-}$, and involve $\mathrm{AB}$ to a $\mathrm{Si}$ site. Note that the differences in $x$-coordinates between the different atomic hops in Figure 3 only correspond to the number of intermediate images employed in the CI-NEB calculations, and do not reflect absolute distances in the supercell.

The potential energy surfaces for $\mathrm{H}_{i}^{-}$migration (Fig. 3c) are strikingly different from those of $\mathrm{H}_{i}^{+}$, having either a single transition state near mid-way along the path (axial jump), or two transition states similar in energy with a small local minimum in between (both basal jumps). In the former case, the transition state occurs as $\mathrm{H}_{i}^{-}$passes through a square constructed of two $\mathrm{C}$ and two $\mathrm{Si}$ atoms. For basal $(k)$ migration (blue curve), the first transition state of $\mathrm{H}_{i}^{-}$is anti-bonded to $\mathrm{C}(h)$, while the subsequent local minimum and second barrier involve a rotation of the bond, and passing between two $\mathrm{Si}$ atoms on the way to the final configuration $(\mathrm{AB}$ to $\mathrm{Si}(k))$. The transition state for $\mathrm{H}_{i}$ that is $\mathrm{AB}$ to $\mathrm{Si}(h)$ (red curve in Fig. 3c) is, in fact, similar to the $\mathrm{AB}$ to $\mathrm{Si}(k)$ configuration, with the difference being that the former is stable when the three basal atoms are $\mathrm{Si}(h)$, while the latter is stable when they are $\mathrm{Si}(k)$. Therefore, for the negative charge state in particular, we find a pronounced effect of the crystal field (depending on whether the $\mathrm{H}$ atom resides in a $h$ or $k$ lattice plane) on the preferred configuration of interstitial hydrogen.

\section{The $V_{S i^{-}} H$ complex}

If a silicon vacancy is present in the material, $\mathrm{H}$ may prefer the substitutional over the interstitial configuration. The formation energy diagrams of $V_{\mathrm{Si}}-\mathrm{H}$ (calculated as described in Section II) and $V_{\mathrm{Si}}$ (calculated as in Ref. [9]) are presented in Figure 4. We observe that while the formation energy of $\mathrm{H}_{i}$ is significantly lower than that of the $V_{\mathrm{Si}}-\mathrm{H}$ complex for all Fermi levels, the $V_{\mathrm{Si}}-\mathrm{H}$ complex will be energetically favorable if $V_{\mathrm{Si}}$ is present in the material. Indeed, after proton implantation both $V_{\mathrm{Si}}$ and $\mathrm{H}$ are present, and the formation of $V_{\mathrm{Si}}-\mathrm{H}$ is likely.

For the $V_{\mathrm{Si}}-\mathrm{H}$ complex, we find that the $\mathrm{H}$ atom prefers to sit closer to the axial or one of the three basal $\mathrm{C}$ atoms (termed the axial and basal configurations, respectively). The four configurations differ in energy by less than $0.1 \mathrm{eV}$ for $V_{\mathrm{Si}}(h)-\mathrm{H}$, and all configurations are expected to be available to both com-

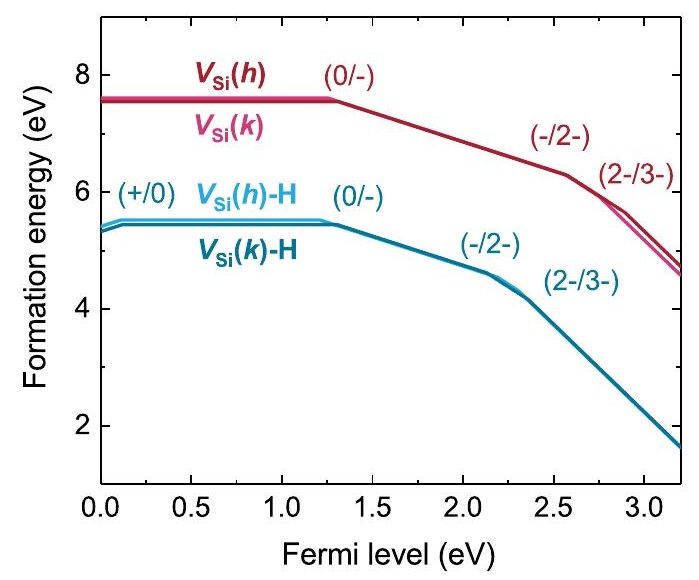

FIG. 4. Formation energy diagram for the silicon vacancy and the $V_{\mathrm{Si}}-\mathrm{H}$ complex, in both the $h$ and $k$ configurations. The total energies of $V_{\mathrm{Si}}$ are from Ref. [9], and the VBM energy is offset to zero. 


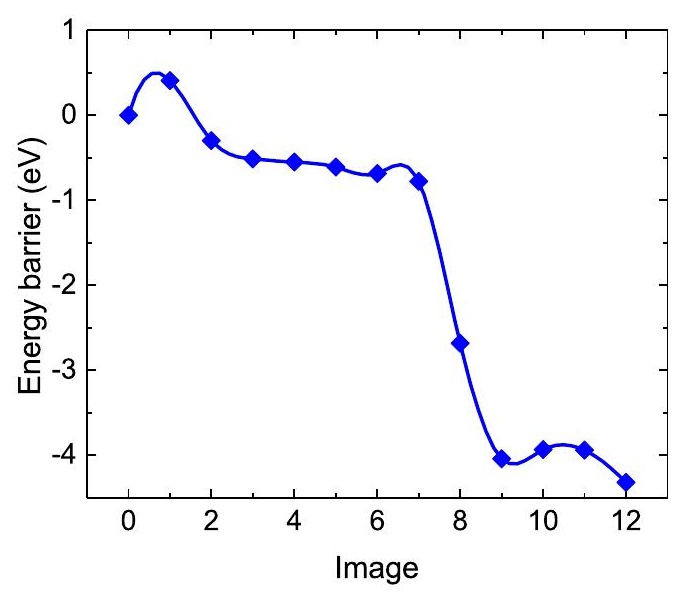

FIG. 5. Minimum energy path for dissociation of $\left(V_{\mathrm{Si}}(k)-\mathrm{H}\right)^{3-}$, as calculated using the CI-NEB method, the PBE functional and $\Gamma$-only $\mathrm{BZ}$ sampling. The starting image was $V_{\mathrm{Si}}(k)$ with a $\mathrm{H}$ atom two lattice vectors away. The solid lines are cubic-spline interpolations of the data obtained from CI-NEB calculations, and are intended as eyeguides.

plexes ( $h$ and $k$ ) at room temperature. The $\mathrm{C}-\mathrm{H}$ bond length is between 1.10-1.11 $\AA$ for all charge states and both $h$ and $k$ $V_{\mathrm{Si}}$, in close agreement with the $1.12 \AA$ found for $\mathrm{C}-\mathrm{H}$ bonds in 3C-SiC [19]. Similarly to that for $V_{\mathrm{Si}}$, the $\mathrm{C}$ atoms surrounding the $V_{\mathrm{Si}}-\mathrm{H}$ complex experience a slight breathing relaxation, which is more prominent for the positive and neutral charge states than for the three acceptor states. Contrary to what is found for $V_{\mathrm{Si}}$, the $V_{\mathrm{Si}}-\mathrm{H}$ complex is more stable in the $k$ than $h$ configuration in p-type and slightly n-type material, and vice versa in highly n-type material, although the difference in stability is minor (see Fig. 4). Interestingly, the shape of the formation energy diagram is strikingly similar for $V_{\mathrm{Si}}$ and $V_{\mathrm{Si}}-\mathrm{H}$, with only minor differences apart from the predicted stability of $\left(V_{\mathrm{Si}^{-}} \mathrm{H}\right)^{+}$in highly p-type $4 \mathrm{H}-\mathrm{SiC}$.

Next, we consider the binding energy of $V_{\mathrm{Si}^{-}}-\mathrm{H}$. Importantly, to ensure that silicon vacancies do not inadvertently disappear, processing steps intended for quantum applications utilizing $V_{\mathrm{Si}}$ should not involve heat treatments exceeding $400-600{ }^{\circ} \mathrm{C}$ $[5,9,44,45]$. In this temperature range, the Fermi level resides around $0.5 \mathrm{eV}$ below the conduction band edge in n-type material, and the $V_{\mathrm{Si}}-\mathrm{H}$ complex will likely inhabit the $3-$ charge

TABLE II. Spin state of $V_{\mathrm{Si}}$ and the $V_{\mathrm{Si}}-\mathrm{H}$ complexes, as calculated using hybrid DFT for different charge states. The results for $V_{\mathrm{Si}}(h)$ and $V_{\mathrm{Si}}(k)$ are from Ref. [9].

\begin{tabular}{lcccr}
\hline \hline Charge state & $V_{\mathrm{Si}}(k)$ & $V_{\mathrm{Si}}(h)$ & $V_{\mathrm{Si}}(k)-\mathrm{H}$ & $V_{\mathrm{Si}}(h)-\mathrm{H}$ \\
\hline$q=+$ & $\mathrm{N} / \mathrm{A}$ & $\mathrm{N} / \mathrm{A}$ & 0 & 1 \\
$q=0$ & 1 & 1 & $3 / 2$ & $3 / 2$ \\
$q=-$ & $3 / 2$ & $3 / 2$ & 1 & 1 \\
$q=2-$ & 1 & 1 & $1 / 2$ & $1 / 2$ \\
$q=3-$ & $1 / 2$ & $1 / 2$ & 0 & 0 \\
\hline \hline
\end{tabular}

state (see Fig. 4). If the defect dissociates into $\left(V_{\mathrm{Si}^{-}} \mathrm{H}\right)^{2-}+\mathrm{H}_{i}^{-}$, the energy raises by $4.35 \mathrm{eV}$ (binding energy). Of course, the dissociation kinetics are limited by a dissociation barrier, which must be at least as high as the binding energy plus the migration barrier of the faster-diffusing product. These figures ensure that $V_{\mathrm{Si}}-\mathrm{H}$ will remain stable in n-type $4 \mathrm{H}-\mathrm{SiC}$ at most operating conditions. Interestingly, Refs. [46,47] predicted that dissociation of complexes between $V_{\mathrm{Si}}$ and $\mathrm{H}$ is the rate limiting step for $\mathrm{H}$ diffusion in irradiated n-type $4 \mathrm{H}$ and $6 \mathrm{H} \mathrm{SiC}$, with dissociation energies being in the 3.5-4.9 eV range. The relevant experimental conditions involve temperatures above $1300{ }^{\circ} \mathrm{C}$ [48], resulting in Fermi levels around midgap and leaving $\mathrm{H}_{i}$ in the positive charge state. The binding energy of $V_{\mathrm{Si}}-\mathrm{H}$ will then likely differ from the n-type case.

Dissociation of $\left(V_{\mathrm{Si}}-\mathrm{H}\right)^{3-}$ into the relevant constituents was studied using CI-NEB and a starting configuration with the $\mathrm{H}$ atom situated approximately two lattice vectors away from the vacancy (to enable relaxation). The resulting MEP is shown in Figure 5, and we find that the dissociation barrier is indeed the binding energy plus the migration barrier of $\mathrm{H}_{i}$, with no large capture barriers being present. In n-type $4 \mathrm{H}-\mathrm{SiC}$, where migration of $\mathrm{H}_{i}$ was found to have $E_{\mathrm{A}}$ above $2.2 \mathrm{eV}$ (at the PBE-level), we anticipate that migration of interstitial hydrogen is the limiting reaction for $V_{\mathrm{Si}}-\mathrm{H}$ complex formation.

The silicon vacancy is a promising candidate for quantum technology applications, having millisecond spin coherence times and single-photon emission associated with the negative charge state. It is thus relevant to consider the effect of hydrogen on the electro-optical properties of $V_{\mathrm{Si}}$ when an isolated vacancy is transformed into the $V_{\mathrm{Si}}-\mathrm{H}$ defect complex. As only the negative charge state $\left(V_{\mathrm{Si}}^{-}\right)$has well-known opto-spin signals, it is particularly interesting to scrutinize the energetics of $V_{\mathrm{Si}}-\mathrm{H}$ as compared to that of $V_{\mathrm{Si}}^{-}$.

Table II summarizes the ground state total spin of both $V_{\mathrm{Si}}$ configurations and the $V_{\mathrm{Si}}-\mathrm{H}$ complexes for all relevant charge states. Interestingly, $\left(V_{\mathrm{Si}}-\mathrm{H}\right)^{+}$appears to change spin states between the $h$ and $k V_{\mathrm{Si}}$ configurations. This happens because the electronic structure of $\left(V_{\mathrm{Si}}(k)-\mathrm{H}\right)^{+}$organizes as $a_{1}^{2} e^{0}$, while in $\left(V_{\mathrm{Si}}(h)-\mathrm{H}\right)^{+}$the $a_{1}$ and $e$ levels become very close, resulting in a parallel spin configuration.

In the negative charge state, the ground state spin of $V_{\mathrm{Si}}(h$ and $k$ ) is $S=3 / 2$. We observe that a corresponding high-spin configuration does exist for the $V_{\mathrm{Si}}-\mathrm{H}$ complex, but now in the neutral charge state. This is so because the reaction of $V_{\mathrm{Si}}^{-}$ with $\mathrm{H}^{+}$displaces one of the singlet gap states of $V_{\mathrm{Si}}^{-}$into the valence band (due to $\mathrm{C}-\mathrm{H}$ bond formation), along with two electrons. However, magnetic and optical manipulation of the $V_{\mathrm{Si}}$ spin state, as needed for quantum applications, relies on optical detection of the V1 and V2 ZPLs. Accordingly, a crucial question is whether photoluminescence from $V_{\mathrm{Si}}-\mathrm{H}$ follows that of $V_{\mathrm{Si}}$. Although they do not provide the full picture, the Kohn-Sham single-particle states that result from DFT calculations may illuminate how the electronic structure of $V_{\mathrm{Si}}$ changes upon addition of $\mathrm{H}$ to form the $V_{\mathrm{Si}}-\mathrm{H}$ complex.

The five upper electrons inhabiting the $V_{\mathrm{Si}}^{-}$defect states are expected to distribute in an $a_{1}^{2} a_{1}^{1} e^{2}$ configuration in the ground state, with the first excited state (V1 and V2) being $a_{1}^{1} a_{1}^{2} e^{2}$ [49]. Accordingly, the optical transitions are minority spin- 
Photon Energy (eV)

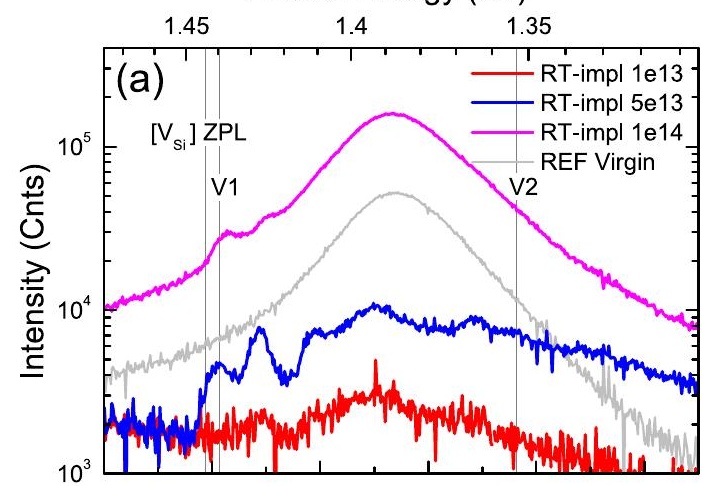

(b)

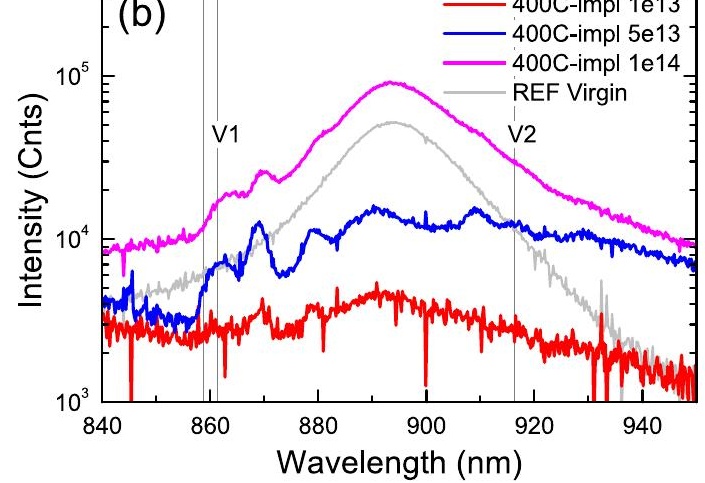

FIG. 6. Emission from n-type $4 \mathrm{H}-\mathrm{SiC}$ (proton implanted to different fluences) collected at $10 \mathrm{~K}$, for implantation at (a) RT and (b) $400{ }^{\circ} \mathrm{C}$, with the $V_{\mathrm{Si}}$-related emission lines $\mathrm{V} 1$ and $\mathrm{V} 2$ highlighted.

channel transitions. The relevant charge states of $V_{\mathrm{Si}}-\mathrm{H}$ are $q=-, 2-$ and $3-$, as these are most likely present in $\mathrm{n}$ type material. $V_{\mathrm{Si}}$ is metastable in p-type $4 \mathrm{H}-\mathrm{SiC}$, and rapidly transforms into $\mathrm{C}_{\mathrm{Si}} V_{\mathrm{C}}$ for Fermi levels below mid-gap. The electronic structures of $V_{\mathrm{Si}}-\mathrm{H}$ are $a_{1}^{2} e^{2}, a_{1}^{2} e^{3}$ and $a_{1}^{2} e^{4}$ for the charge states - 2- and 3-, respectively. Indeed, the - and 2 - states could have excited states similar to V1', where an electron from the singlet is promoted to the doublet. However, upon comparing, e.g., $V_{\mathrm{Si}}(k)^{-}$to $\left(V_{\mathrm{Si}}(k)-\mathrm{H}\right)^{0}$, we observe that there are no longer any occupied spin-down energy levels within the band gap for the complex. All spin-down electrons are confined to the valence band. Moreover, there are only two unoccupied levels within the gap, as compared to four for $V_{\mathrm{Si}}$. Upon complex formation the energy difference between the highest occupied and lowest unoccupied Kohn-Sham energy levels is lowered by $\sim 0.6 \mathrm{eV}$, indicating a drastic change in emission when $V_{\mathrm{Si}}$ transforms into $V_{\mathrm{Si}}-\mathrm{H}$. Moreover, the $3-$ state does not have excited states because the levels are fully occupied, and thus formation of $\left(V_{\mathrm{Si}}-\mathrm{H}\right)^{q}$ complexes may explain the PL quenching.

To summarize, we find from theoretical considerations that the $V_{\mathrm{Si}}-\mathrm{H}$ complex is stable in n-type $4 \mathrm{H}-\mathrm{SiC}$, with thermal formation (given the presence of $V_{\mathrm{Si}}$ ) restricted by the migration barrier of interstitial hydrogen. Even though high-spin configurations likely exist for the $V_{\mathrm{Si}}-\mathrm{H}$ complex, capturing an $\mathrm{H}$ atom is found to significantly impact the electronic configuration of $V_{\mathrm{Si}}$, resulting in an alteration of the optical transition and quenching of $V_{\mathrm{Si}}$-related photoluminescence.

\section{B. Experiment}

In Ref. [18], the effect of $\mathrm{H}$ implantation on $V_{\mathrm{Si}}$-related PL was compared to that of He implantation. Considering the reported results, the assumption that formation of the $V_{\mathrm{Si}}-\mathrm{H}$ complex quenches luminescence from $V_{\mathrm{Si}}$ in turn necessitates that $\mathrm{He}$ does not complex with $V_{\mathrm{Si}}$, or that $V_{\mathrm{Si}}-\mathrm{He}$ complexes retain the luminescence properties of isolated $V_{\mathrm{Si}}$. Herein, we investigate the effect of fluence and temperature during hydrogen implantation on the $V_{\mathrm{Si}}$ luminescence intensity, to corroborate the theoretical predictions above.

Figure 6 shows the effect of different proton fluences on $V_{\mathrm{Si}}$-related emission for (a) RT and (b) $400{ }^{\circ} \mathrm{C}$ hydrogen implantation. One can observe dramatic developments in the PL spectra of $4 \mathrm{H}-\mathrm{SiC}$ upon irradiation, with the broad background emission (gray band) representing the virgin material being quenched after the lowest fluence irradiation and then gradually recovering at higher fluences. The intensity of the silicon vacancy-related signal is increasing with the proton fluence, and such a dependency remains linear within the $10^{11}-10^{14} \mathrm{~cm}^{-2}$ fluence range, as shown earlier in Ref. [9]. Upon comparing Figures 6(a) and 6(b), we notice that the signal intensity overall increases for the $400{ }^{\circ} \mathrm{C}$ implant, while $V_{\mathrm{Si}}$-related features seem to sharpen. This effect can be attributed to the reduction in non-radiative channels at elevated temperatures.

Figure 7 displays a baseline-subtracted and zoomed-in version of Figure 6, and compares RT and $400{ }^{\circ} \mathrm{C}$ irradiation for the three different proton fluences (a-c). In Figure 7(a), for the lowest proton fluence, the V1 and V2 ZPLs are barely visible as the $V_{\mathrm{Si}}$ concentration is below the detection level, but the elevated temperature seems to enhance the overall signal. Both V1 and V2 are clearly visible in Figures 7(b) and 7(c), with $\mathrm{V} 1$ being much more prominent than V2. The total luminescence and amount of features appear greater for the $400{ }^{\circ} \mathrm{C}$ implant in all three cases. For the intermediate case, illustrated in Figure 7 (b), irradiating at $400{ }^{\circ} \mathrm{C}$ clearly impacts the $V_{\mathrm{Si}}$ content in the sample compared to that of the RT sample. The $\mathrm{V} 1$ peak is almost twice as strong for the high temperature irradiation. The moderate proton fluence of $5 \times 10^{13} \mathrm{~cm}^{-2}$ falls within the scope studied in Ref. [9], where we correlate the proton fluence dependence of the V1 emission intensity to the same dependence of the $\mathrm{S}$ center observed in DLTS spectra of n-type $4 \mathrm{H}-\mathrm{SiC}$. Therefore, we can conclude that an increase in $\mathrm{V} 1$ intensity is accompanied by a similar increase in the $V_{\mathrm{Si}}$ concentration. Consequently, for the medium fluence $\left(5 \times 10^{13} \mathrm{~cm}^{-2}\right)$, we can anticipate more silicon vacancies and fewer non-radiative channels for the sample irradiated at $400{ }^{\circ} \mathrm{C}$ than the one irradiated at RT.

Interestingly, Figure 7(c) demonstrates the opposite behavior for V1 when comparing to Figure 7(b). In fact, the V1 peak is found to be stronger after implanting at RT than at $400{ }^{\circ} \mathrm{C}$ for the highest proton fluence. The discrepancy in temperature dependence between Figures 7(b) and 7(c) is intriguing, and challenging to explain from standard considerations con- 

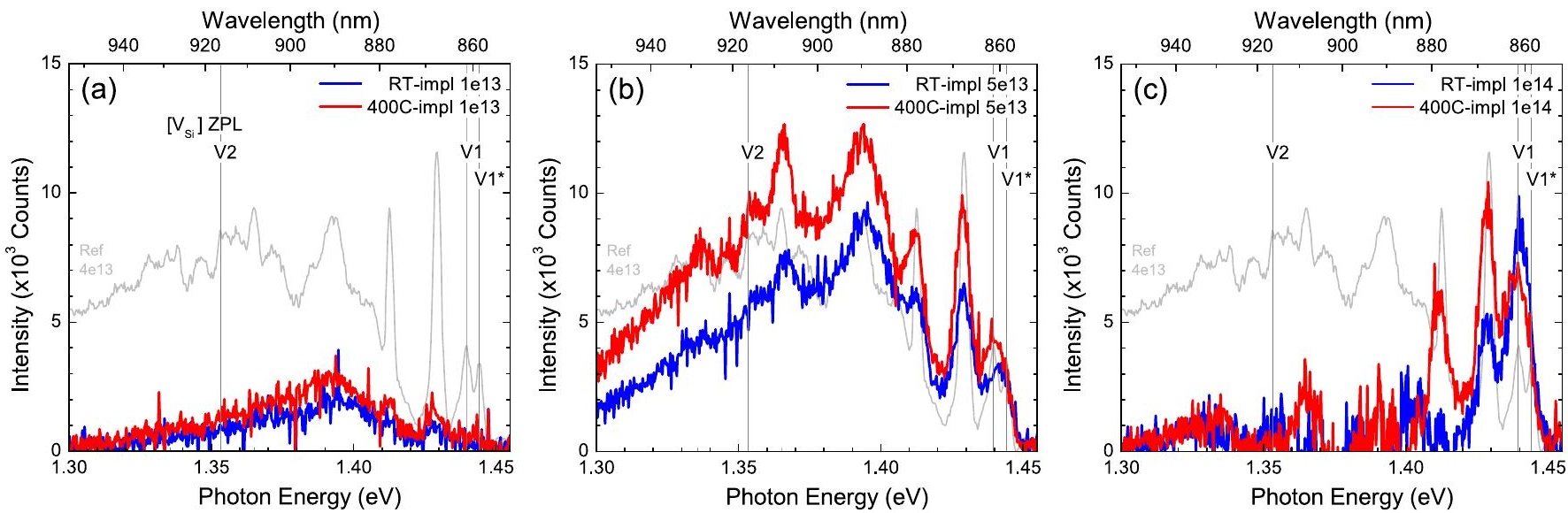

FIG. 7. Emission from n-type $4 \mathrm{H}-\mathrm{SiC}$, proton implanted at RT (blue lines) and $400{ }^{\circ} \mathrm{C}$ (red lines), collected at $10 \mathrm{~K}$, for proton fluences of (a) $1 \times 10^{13} \mathrm{~cm}^{-2}$, (b) $5 \times 10^{13} \mathrm{~cm}^{-2}$ and (c) $1 \times 10^{14} \mathrm{~cm}^{-2}$, with the $V_{\mathrm{Si}}$-related $\mathrm{V} 1$ and $\mathrm{V} 2$ emission lines highlighted. The gray PL spectra in the background are for reference, and derive from a $V_{\mathrm{Si}}$-rich sample from Ref. [9].

cerning irradiation and temperature alone.

\section{DISCUSSION}

The DFT calculations corroborate that hydrogen migrates faster in p-type material than in n-type, as previously established experimentally [42]. However, raising the temperature above $400{ }^{\circ} \mathrm{C}$ during implantation could render the $\mathrm{H}$ atoms mobile, even in n-type material. Accordingly, during hot implantation $\mathrm{H}$ is likely to migrate, and potentially encounter an implantation-induced and nearby $V_{\mathrm{Si}}$ and form $V_{\mathrm{Si}}-\mathrm{H}$ complexes, resulting in reduced emission from $V_{\mathrm{Si}}$ centers. Indeed, $\mathrm{H}$ migration in irradiated material is expected to be limited by dissociation of H-related complexes [46,47], with outdiffusion of $\mathrm{H}$ not commencing until above $1300{ }^{\circ} \mathrm{C}$ [48].

Post-implantation annealing should result in a similar effect on $V_{\mathrm{Si}}$ as that of hot implantation. Indeed, Wang et al. [18] demonstrated that the $V_{\mathrm{Si}}$-related PL increased in intensity after post $\mathrm{H}$-implantation anneals up to $300{ }^{\circ} \mathrm{C}$, while He-implantation resulted in increasing PL intensities up to $500{ }^{\circ} \mathrm{C}$. Importantly, silicon vacancies are metastable in ntype $4 \mathrm{H}-\mathrm{SiC}$, and anneal out between $400-600{ }^{\circ} \mathrm{C}$ [5]. Hence, one may speculate that the lower stability of $V_{\mathrm{Si}}$ after $\mathrm{H}$ implantation as compared to that of He may be related to formation of $V_{\mathrm{Si}}-\mathrm{H}$, and larger complexes thereof, assuming that $\mathrm{H}$ becomes mobile at or above $400{ }^{\circ} \mathrm{C}$.

The experiments demonstrate different effects of temperature on $V_{\mathrm{Si}}$-related emission, depending on the proton fluence used for hydrogen implantation (Fig. 7). Firstly, C and Si interstitials are expected to migrate rapidly at $400{ }^{\circ} \mathrm{C}$, but not at $\mathrm{RT}$, due to migration barriers of $\sim 1 \mathrm{eV}[50]$ resulting in fewer non-radiative channels in the samples irradiated at $400{ }^{\circ} \mathrm{C}$ as compared to the RT ones. Secondly, $V_{\mathrm{Si}}$ defects may start to anneal out in this temperature range, due to migration of $\mathrm{H}_{i}$, recapturing of self-interstitials or transformation into $\mathrm{C}_{\mathrm{Si}} V_{\mathrm{C}}$ [5]. The migration of $\mathrm{H}_{i}$ and subsequent complex formation would be dependent on the average distance between $V_{\mathrm{Si}}$ 's, and hence fluence dependent.

The diffusivity $D$ of hydrogen is expected to follow an $\mathrm{Ar}-$ rhenius behavior in $4 \mathrm{H}-\mathrm{SiC}$, according to

$$
D=D_{0} e^{-E_{\mathrm{A}} / k T},
$$

where $D_{0}$ is the exponential prefactor, $E_{\mathrm{A}}$ the activation energy for migration, $k$ the Boltzmann constant and $T$ the temperature [29]. If we assume that $D_{0}=4 \times 10^{-3} \mathrm{~cm}^{2} / \mathrm{s}$ for $\mathrm{H}$ [51] and $L=\sqrt{D t}$, and estimate that the samples are at $400^{\circ} \mathrm{C}$ for $t=1$ hour, the diffusion length of $\mathrm{H}_{i}$ becomes $L=22 \mathrm{~nm}$ for a migration barrier of $E_{\mathrm{A}}=2.2 \mathrm{eV}$ (see Table I). Using SRIM, we estimate that the $V_{\mathrm{Si}}$ concentration at the top of the implantation Bragg peak is $1.3 \times 10^{16} \mathrm{~cm}^{-3}$ for the low fluence $\left(10^{13} \mathrm{~cm}^{-2}\right), 7 \times 10^{16} \mathrm{~cm}^{-3}$ for the medium fluence $\left(5 \times 10^{13} \mathrm{~cm}^{-2}\right)$ and $1.3 \times 10^{17} \mathrm{~cm}^{-3}$ for the high fluence $\left(10^{14} \mathrm{~cm}^{-2}\right)$, assuming a dynamic annealing factor of $3 \%$ for $V_{\mathrm{Si}}$ [9]. These concentrations translate into mean distances between silicon vacancies (in all directions) of approximately $45 \mathrm{~nm}, 25 \mathrm{~nm}$ and $20 \mathrm{~nm}$, respectively. As the peak concentration of $\mathrm{H}$ is 3-4 times larger than that of $\mathrm{Si}$ vacancies, we assume that formation of $V_{\mathrm{Si}}-\mathrm{H}$ is limited by the $V_{\mathrm{Si}}$ distribution. Hence, for the low fluence $\left(10^{13} \mathrm{~cm}^{-2}\right)$ and medium fluence $\left(5 \times 10^{13} \mathrm{~cm}^{-2}\right)$ the diffusion length of $\mathrm{H}_{i}$ is not sufficient to efficiently form $V_{\mathrm{Si}}-\mathrm{H}$, while for the high fluence $\left(10^{14} \mathrm{~cm}^{-2}\right)$ complex formation is viable, and is one potential explanation for the fluence dependence observed in Figure 7, and the temperature dependence observed in Ref. [18].

In conclusion, we find that the likelihood of a hydrogen atom diffusing far enough to encounter, and potentially form a complex with, a silicon vacancy increases with the proton irradiation fluence. Hence, hot hydrogen implantation might render $\mathrm{H}$ mobile and increase the amount of $V_{\mathrm{Si}}-\mathrm{H}$ complexes as compared to the corresponding RT process. If maximum yield of isolated $V_{\mathrm{Si}}$ defects is desired and a sample volume containing the Bragg peak of $\mathrm{H}$ is to be probed, hydrogen should be avoided as the implantation species, with He being a more promising candidate. Alternatively, the issue can be circumvented by laser creation of point defects, as recently 
demonstrated for $V_{\mathrm{Si}}$ in silicon carbide [52,53].

So far, no optical signal has been unambiguously assigned to complexes of $V_{\mathrm{Si}}$ and $\mathrm{H}$, as the $\mathrm{H}$-lines, which are located around $3.15 \mathrm{eV}$ in hydrogen-rich $4 \mathrm{H}-\mathrm{SiC}$ and were originally assigned to $V_{\mathrm{Si}}-\mathrm{H}$ [54], were later attributed to a hydrogen dimer bound to a carbon antisite $\left(\mathrm{C}_{\mathrm{Si}} \mathrm{H}_{2}\right)$ [55]. Hence, we remain unable to directly probe $V_{\mathrm{Si}}-\mathrm{H}$ formation. Electrical characterization may offer a viable alternative, as deep level transient spectroscopy (DLTS) measurements of n-type 4H$\mathrm{SiC}$ have shown that hydrogen-related and irradiation-induced defects introduce deep levels within the $4 \mathrm{H}-\mathrm{SiC}$ band gap [20]. Recently, we demonstrated that the silicon vacancy is electrically active in n-type $4 \mathrm{H}-\mathrm{SiC}$, by assigning the $(-/ 2-)$ and $(2-/ 3-)$ charge state transitions of $h$ and $k V_{\mathrm{Si}}$ to the S-center, a deep-level defect consisting of two different transition levels that are sporadically observed in DLTS spectra of n-type $4 \mathrm{H}-\mathrm{SiC}$ [9]. Interestingly, the predicted transition levels of $V_{\mathrm{Si}}-\mathrm{H}$ are $\sim 0.1 \mathrm{eV}, 1.2-1.3 \mathrm{eV}, 2.2 \mathrm{eV}$ and $2.3-2.4 \mathrm{eV}$ above the valence band maximum (Fig. 4), which is within the range found for hydrogen-related deep levels using DLTS [20]. However, complexes between hydrogen and carbon vacancies $\left(V_{\mathrm{C}}-\mathrm{H}\right)$ may also be electrically active [56], and are thus potential candidates for the measured defect levels.

The contribution of the zero-point (vibrational) energy has not been considered herein. Indeed, $\mathrm{H}$ is very light, and the energy of each configuration should have the contribution of approximately $\hbar \omega / 2$, where $\omega$ is the vibrational frequency of the stretch mode for the Si-H or C-H bond. Although it should have a limited impact on the calculated location of electronic levels, zero-point motion affects formation and migration energies (see for instance Ref. [57]). For migration, the contribution of vibration to the energy barrier is expected to be found mainly in the ground state, as the transition state bonds are weaker than the ground state ones. Thus, we expect the absolute error bar of our calculations, arising from vibrations of light $\mathrm{H}$ atoms, to be in the 0.1-0.2 eV range (see Ref. [19]).

\section{CONCLUDING REMARKS}

In summary, we study hydrogen-related defects in $4 \mathrm{H}-\mathrm{SiC}$, and find that $\mathrm{H}_{i}$ may exist both interstitially and embedded in defect complexes. As previously found, $\mathrm{H}_{i}$ is expected to migrate much faster in p-type than n-type $4 \mathrm{H}-\mathrm{SiC}$ material, and migration of $\mathrm{H}$ may be limited by formation of complexes such as $V_{\mathrm{Si}^{-}}-\mathrm{H}$ in $\mathrm{n}-4 \mathrm{H}-\mathrm{SiC}$. In fact, the $V_{\mathrm{Si}^{-}}-\mathrm{H}$ complex is more stable than the isolated $V_{\mathrm{Si}}$ defect, and we find it likely that hydrogen may alter the spin and luminescence properties of $V_{\mathrm{Si}}$ in n-type $4 \mathrm{H}-\mathrm{SiC}$. Upon comparing to $\mathrm{PL}$ emission from n-type $4 \mathrm{H}-\mathrm{SiC}$ samples that are proton irradiated to different fluences and at different temperatures, we find that elevated temperature implantations may induce $\mathrm{H}_{i}$ motion, causing formation of $V_{\mathrm{Si}^{-}} \mathrm{H}$ complexes and a reduction in the $V_{\mathrm{Si}^{-}}$ related emission intensity. In conclusion, we predict that hydrogen could present an important obstacle towards reliable formation of, and optimal luminescence yield from, $V_{\mathrm{Si}}$ defects highly suitable for quantum technology applications.

\section{ACKNOWLEDGMENTS}

Financial support was kindly provided by the Research Council of Norway and the University of Oslo through the frontier research project FUNDAMeNT (no. 251131, FriPro ToppForsk-program), and the Norwegian Micro- and Nanofabrication Facility (NorFAB 245963). The computations were performed on resources provided by UNINETT Sigma2 - the National Infrastructure for High Performance Computing and Data Storage in Norway. J.C. thanks the Fundação para a Ciência e a Tecnologia (FCT) for support under project UID/CTM/50025/2019, co-funded by FEDER funds through the COMPETE 2020 Program.

${ }^{1}$ J. R. Weber, W. F. Koehl, J. B. Varley, A. Janotti, B. B. Buckley, C. G. V. de Walle, and D. D. Awschalom, "Quantum computing with defects," Proceedings of the National Academy of Sciences 107, 8513-8518 (2010).

${ }^{2}$ S. Castelletto, L. Rosa, and B. C. Johnson, "Silicon carbide for novel quantum technology devices," in Advanced Silicon Carbide Devices and Processing (InTech, 2015)

${ }^{3}$ E. Janzén, A. Gali, P. Carlsson, A. Gällström, B. Magnusson, and N. Son, "The silicon vacancy in SiC," Physica B: Condensed Matter 404, 4354-4358 (2009).

${ }^{4}$ D. J. Christle, A. L. Falk, P. Andrich, P. V. Klimov, J. U. Hassan, N. T. Son, E. Janzén, T. Oshima, and D. D. Awschalom, "Isolated electron spins in silicon carbide with millisecond coherence times," Nature Materials 14 $160-163$ (2015).

${ }^{5}$ S. Castelletto, B. C. Johnson, V. Ivády, N. Stavrias, T. Umeda, A. Gali, and T. Oshima, "A silicon carbide room-temperature single-photon source," Nature Materials 13, 151-156 (2014).

${ }^{6}$ H. J. von Bardeleben, J. L. Cantin, A. Csóré, A. Gali, E. Rauls, and U. Gerstmann, "NV centers in $3 \mathrm{C}, 4 \mathrm{H}$, and $6 \mathrm{H}$ silicon carbide: A variable platform for solid-state qubits and nanosensors," Physical Review B 94, 121202(R) (2016).

${ }^{7}$ R. Nagy, M. Widmann, M. Niethammer, D. B. R. Dasari, I. Gerhardt, Ö. O. Soykal, M. Radulaski, T. Oshima, J. Vucković, N. T. Son, I. G. Ivanov, S. E. Economou, C. Bonato, S.-Y. Lee, and J. Wrachtrup, "Quantum properties of dichroic silicon vacancies in silicon carbide," Physical Review Applied 9, 034022 (2018).

${ }^{8}$ R. Nagy, M. Niethammer, M. Widmann, Y.-C. Chen, P. Udvarhelyi, C. Bonato, J. U. Hassan, R. Karhu, I. G. Ivanov, N. T. Son, J. R. Maze, T. Oshima, Ö. O. Soykal, A. Galí, S.-Y. Lee, F. Kaiser, and J. Wrachtrup, "High-fidelity spin and optical control of single silicon-vacancy centres in silicon carbide," Nature Communications 10, 1054 (2019).

${ }^{9}$ M. E. Bathen, A. Galeckas, J. Müting, H. M. Ayedh, U. Grossner, J. Coutinho, Y. K. Frodason, and L. Vines, "Electrical charge state identification and control for the silicon vacancy in 4H-sic," Accepted for publication in npj Quantum Information (2019).

${ }^{10}$ C. P. Anderson, A. Bourassa, K. C. Miao, G. Wolfowicz, P. J. Mintun, A. L. Crook, H. Abe, J. U. Hassan, N. T. Son, T. Oshima, and D. D. Awschalom, "Electrical and optical control of single spins integrated in scalable semiconductor devices," (2019).

${ }^{11}$ C. F. de la Casas, D. J. Christle, J. U. Hassan, T. Ohshima, N. T. Son, and D. D. Awschalom, "Stark tuning and electrical charge state control of single divacancies in silicon carbide," Applied Physics Letters 111, 262403 (2017).

${ }^{12}$ M. Wagner, B. Magnusson, W. M. Chen, E. Janzén, E. Sörman, C. Hallin, and J. L. Lindström, "Electronic structure of the neutral silicon vacancy in 4H and 6H sic," Physical Review B 62, 16555 (2000).

${ }^{13}$ M. Widmann, S.-Y. Lee, T. Rendler, N. T. Son, H. Fedder, S. Paik, L.-P Yang, N. Zhao, S. Yang, I. Booker, A. Denisenko, M. Jamali, S. A. Momenzadeh, I. Gerhardt, T. Ohshima, A. Gali, E. Janzén, and J. Wrachtrup, "Coherent control of single spins in silicon carbide at room temperature," Nature Materials 14, 164-168 (2014).

${ }^{14}$ M. Radulaski, M. Widmann, M. Niethammer, J. L. Zhang, S.-Y. Lee, T. Rendler, K. G. Lagoudakis, N. T. Son, E. Janzén, T. Oshima, J. Wrachtrup, and J. Vucković, "Scalable quantum photonics with single color centers in silicon carbide," Nano Letters 17, 1782-1786 (2017). 
${ }^{15}$ M. Widmann, M. Niethammer, D. Y. Fedyanin, I. A. Khramtsov, T. Rendler, I. D. Booker, J. U. Hassan, N. Morioka, Y.-C. Chen, I. G. Ivanov, N. T. Son, T. Ohshima, M. Bockstedte, A. Gali, C. Bonato, S.-Y. Lee, and J. Wrachtrup, "Electrical charge state manipulation of single silicon vacancies in a silicon carbide quantum optoelectronic device," Nano Letters 19, 7173-7180 (2019).

${ }^{16}$ B. Zippelius, J. Suda, and T. Kimoto, "High temperature annealing of ntype 4H-SiC: Impact on intrinsic defects and carrier lifetime," Journal of Applied Physics 111, 033515 (2012).

${ }^{17}$ H. Kraus, D. Simin, C. Kasper, Y. Suda, S. Kawabata, W. Kada, T. Honda, Y. Hijikata, T. Ohshima, V. Dyakonov, and G. V. Astakhov, "Threedimensional proton beam writing of optically active coherent vacancy spins in silicon carbide," Nano Letters 17, 2865-2870 (2017).

${ }^{18}$ J.-F. Wang, Q. Li, F.-F. Yan, H. Liu, G.-P. Guo, W.-P. Zhang, X. Zhou, L.-P. Guo, Z.-H. Lin, J.-M. Cui, X.-Y. Xu, J.-S. Xu, C.-F. Li, and G.-C. Guo, "On-demand generation of single silicon vacancy defects in silicon carbide," ACS Photonics 6, 1736-1743 (2019).

${ }^{19}$ B. Aradi, A. Gali, P. Deák, J. E. Lowther, N. T. Son, E. Janzén, and W. J. Choyke, "Ab initio density-functional supercell calculations of hydrogen defects in cubic SiC," Physical Review B 63, 245202 (2001).

${ }^{20}$ G. Alfieri, E. V. Monakhov, B. G. Svensson, and A. Hallén, "Defect energy levels in hydrogen-implanted and electron-irradiated n-type $4 \mathrm{H}$ silicon carbide," Journal of Applied Physics 98, 113524 (2005).

${ }^{21} \mathrm{G}$. Kresse and J. Hafner, "Ab initio molecular dynamics for liquid metals," Physical Review B 47, 558-561 (1993).

${ }^{22}$ G. Kresse and J. Hafner, "Ab initio molecular-dynamics simulation of the liquid-metal-amorphous-semiconductor transition in germanium," Physical Review B 49, 14251-14269 (1994)

${ }^{23} \mathrm{G}$. Kresse and J. Furthmüller, "Efficiency of ab-initio total energy calculations for metals and semiconductors using a plane-wave basis set," Computational Materials Science 6, 15-50 (1996)

${ }^{24} \mathrm{G}$. Kresse and J. Furthmüller, "Efficient iterative schemes for ab initio totalenergy calculations using a plane-wave basis set," Physical Review B 54, 11169-11186 (1996)

${ }^{25}$ P. E. Blöchl, "Projector augmented-wave method," Physical Review B 50 17953-17979 (1994).

${ }^{26}$ J. P. Perdew, K. Burke, and M. Ernzerhof, "Generalized gradient approximation made simple," Physical Review Letters 77, 3865-3868 (1996)

${ }^{27}$ J. Heyd, G. E. Scuseria, and M. Ernzerhof, "Hybrid functionals based on a screened coulomb potential," The Journal of Chemical Physics 118, $8207-8215$ (2003).

${ }^{28}$ A. V. Krukau, O. A. Vydrov, A. F. Izmaylov, and G. E. Scuseria, "Influence of the exchange screening parameter on the performance of screened hybrid functionals," The Journal of Chemical Physics 125, 224106 (2006).

${ }^{29}$ M. E. Bathen, J. Coutinho, H. M. Ayedh, J. U. Hassan, I. Farkas, S. Öberg,

Y. K. Frodason, B. G. Svensson, and L. Vines, "Anisotropic and planeselective migration of the carbon vacancy in SiC: Theory and experiment," Physical Review B 100, 014103 (2019).

${ }^{30} \mathrm{P}$. Grivickas, V. Grivickas, J. Linnros, and A. Galeckas, "Fundamental band edge absorption in nominally undoped and doped 4H-SiC," Journal of Applied Physics 101, 123521 (2007).

${ }^{31}$ S. B. Zhang and J. E. Northrup, "Chemical potential dependence of defect formation energies in GaAs: Application to Ga self-diffusion," Physical Review Letters 67, 2339 (1991).

${ }^{32}$ C. Freysoldt, B. Grabowski, T. Hickel, J. Neugebauer, G. Kresse, A. Janotti, and C. G. V. de Walle, "First-principles calculations for point defects in solids," Reviews of Modern Physics 86, 253-305. (2014).

${ }^{33}$ C. Freysoldt, J. Neugebauer, and C. G. V. de Walle, "Fully Ab Initio Finitesize corrections for charged-defect supercell calculations," Physical Review Letters 102, 016402 (2009).

${ }^{34}$ Y. Kumagai and F. Oba, "Electrostatics-based finite-size corrections for first-principles point defect calculations," Physical Review B 89, 195205 (2014)

${ }^{35}$ H.-P. Komsa, T. T. Rantala, and A. Pasquarello, "Finite-size supercell correction schemes for charged defect calculations," Physical Review B 86, 045112 (2012).

${ }^{36} \mathrm{G}$. Mills and H. Jónsson, "Quantum and thermal effects in $\mathrm{H} 2$ dissociative adsorption: Evaluation of free energy barriers in multidimensional quantum systems," Physical Review Letters 72, 1124-1127 (1994).
${ }^{37}$ G. Mills, H. Jónsson, and G. K. Schenter, "Reversible work transition state theory: application to dissociative adsorption of hydrogen," Surface Science 324, 305-337 (1995).

${ }^{38}$ M. Kaukonen, C. J. Fall, and J. Lento, "Interstitial H and $\mathrm{H} 2$ in $\mathrm{SiC}$," Applied Physics Letters 83, 923 (2003).

${ }^{39}$ X.-Y. Yang, Z. Wang, Y. Lu, Z. Sun, S. Hussain, and P. Zhang, "Firstprinciples study of hydrogen retention and diffusion behaviors in $4 \mathrm{H}-\mathrm{SiC}$,' Supperlattices and Microstructures 122, 362-370 (2018).

${ }^{40}$ J. F. Ziegler, M. Ziegler, and J. Biersack, "SRIM - the stopping and range of ions in matter (2010)," Nuclear Instruments and Methods in Physics Research Section B: Beam Interactions with Materials and Atoms 268, 1818-1823 (2010)

${ }^{41}$ J. Coutinho, V. J. B. Torres, K. Demmouche, and S. Öberg, "Theory of the carbon vacancy in 4H-SiC: Crystal field and pseudo-jahn-teller effects," Physical Review B 96, 174105 (2017).

${ }^{42}$ N. Achtziger, J. Grillenberger, W. Witthuhn, M. K. Linnarsson, M. Janson, and B. G. Svensson, "Hydrogen passivation of silicon carbide by lowenergy ion-implantation," Applied Physics Letters 73, 945-947 (1998).

${ }^{43}$ B. Aradi, P. Deák, and A. Gali, "Diffusion of hydrogen in perfect, p-type doped, and radiation-damaged 4H-SiC," Physical Review B 69, 233202 (2004)

${ }^{44}$ L. Storasta, J. P. Bergman, E. Janzén, A. Henry, and J. Lu, "Deep levels created by low energy electron irradiation in 4H-SiC," Journal of Applied Physics 96, 4909-4915 (2004).

${ }^{45}$ M. L. David, G. Alfieri, E. M. Monakhov, A. Hallén, C. Blanchard, B. G Svensson, and J. F. Barbot, "Electrically active defects in irradiated $4 \mathrm{H}$ SiC," Journal of Applied Physics 95, 4728-4733 (2004).

${ }^{46}$ M. J. K. Linnarsson, J. P. Doyle, and B. G. Svensson, "Diffusion of hydrogen in 6H silicon carbide," in III-Nitride, SiC and Diamond Materials for Electronic Devices, Mater. Res. Soc. Symp. Proc., Vol. 423, edited by D. K. Gaskill, C. D. Brandt, and R. J. Nemanich (Material Research Society, Pittsburgh, 1996) p. 625.

${ }^{47}$ M. Janson, M. K. Linnarsson, A. Hallén, and B. G. Svensson, in Hydrogen in Semiconductors and Metals, Mater. Res. Soc. Symp. Proc., Vol. 513 edited by N. H. Nickel, W. B. Jackson, and R. C. Bowman (Material Research Society, Pittsburgh, 1998) p. 439.

${ }^{48}$ M. K. Linnarsson, M. S. Janson, U. Forsberg, and E. Janzén, "In-diffusion, trapping and out-diffusion of deuterium in $4 \mathrm{H}-\mathrm{SiC}$ substrates," Materials Science Forum 527-529, 637-640 (2006).

${ }^{49}$ V. Ivády, J. Davidsson, N. T. Son, T. Ohshima, I. A. Abrikosov, and A. Gali, "Identification of Si-vacancy related room-temperature qubits in $4 \mathrm{H}$ silicon carbide," Physical Review B 96, 161114(R) (2017).

${ }^{50}$ N. Iwamoto and B. G. Svensson, "Chapter ten - point defects in silicon carbide," in Defects in Semiconductors, Semiconductors and Semimetals, Vol. 91, edited by L. Romano, V. Privitera, and C. Jagadish (Elsevier, 2015) pp. $369-407$.

${ }^{51}$ J. Philibert, Atom movements: Diffusion and mass transport in solids, Monographies de physique (Editions de Physique, 1991).

${ }^{52}$ S. Castelletto, A. F. M. Almutairi, K. Kumagai, T. Katkus, Y. Hayasaki, B. C. Johnson, and S. Juodkazis, "Photoluminescence in hexagonal silicon carbide by direct femtosecond laser writing," Optics Letters 43, 6077-6080 (2018).

${ }^{53}$ Y.-C. Chen, P. S. Salter, M. Niethammer, M. Widmann, F. Kaiser, R. Nagy, N. Morioka, C. Babin, J. Erlekampf, P. Berwian, M. J. Booth, and J. Wrachtrup, "Laser writing of scalable single color centers in silicon carbide," Nano Letters 19, 2377-2382 (2019).

${ }^{54}$ W. J. Choyke and L. Patrick, "Photoluminescence of H- and D-implanted 4H SiC," Physical Review B 9, 3214 (1974).

${ }^{55}$ D. Prezzi, T. A. G. Eberlein, R. Jones, B. Hourahine, P. R. Briddon, and S. Öberg, "Hydrogen-related photoluminescent centers in SiC," Physical Review B 70, 205207 (2004).

${ }^{56}$ A. Gali, B. Aradi, P. Deák, W. J. Choyke, and N. T. Son, "Overcoordinated hydrogens in the carbon vacancy: Donor centers of SiC," Physical Review Letters 84, 4926 (2000).

${ }^{57}$ S. Z. Karazhanov, M. Ganchenkova, and E. S. Marstein, "Vibrational zero point energy for H-doped silicon," Journal of Chemical Physics 601, 49-53 (2014) 

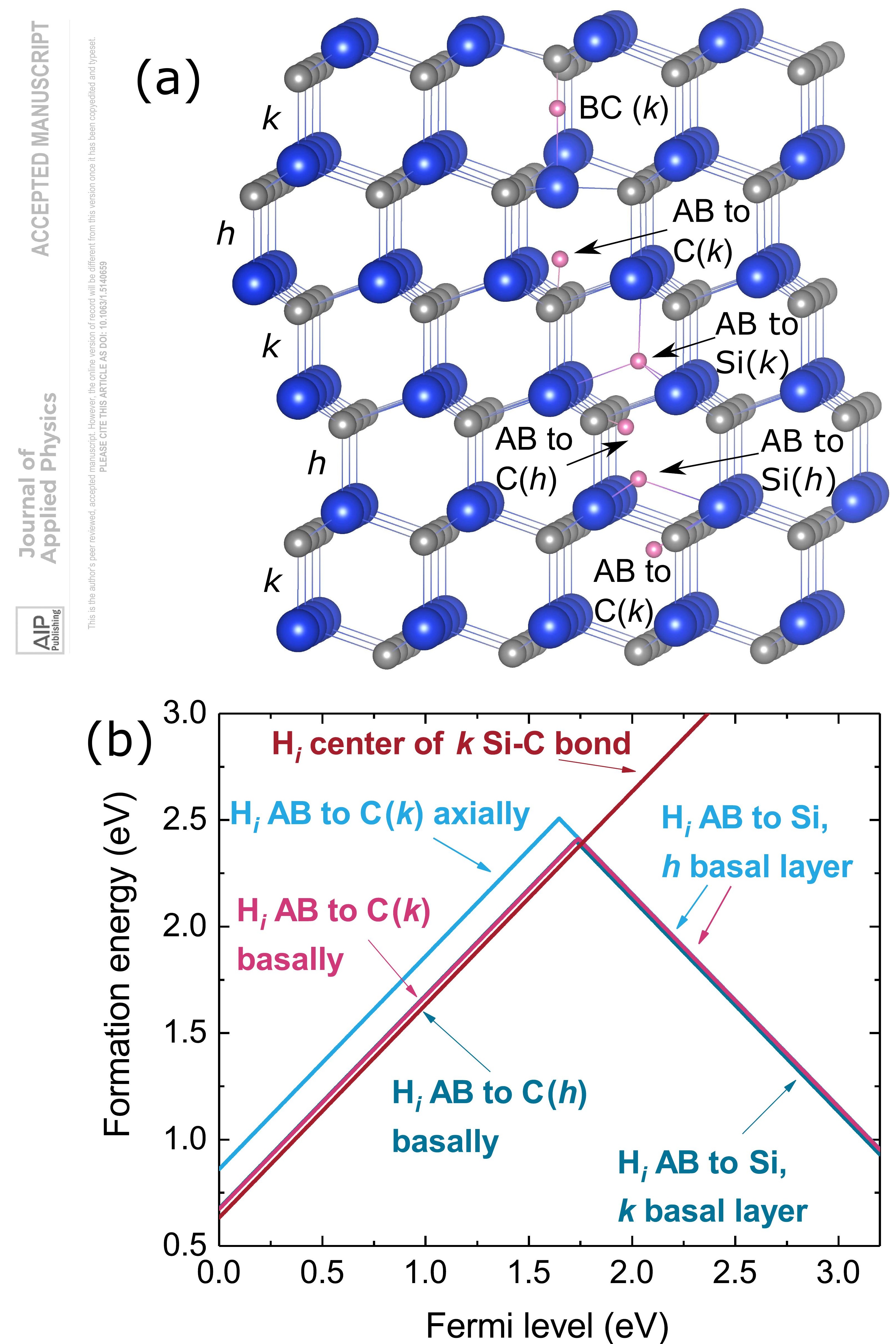

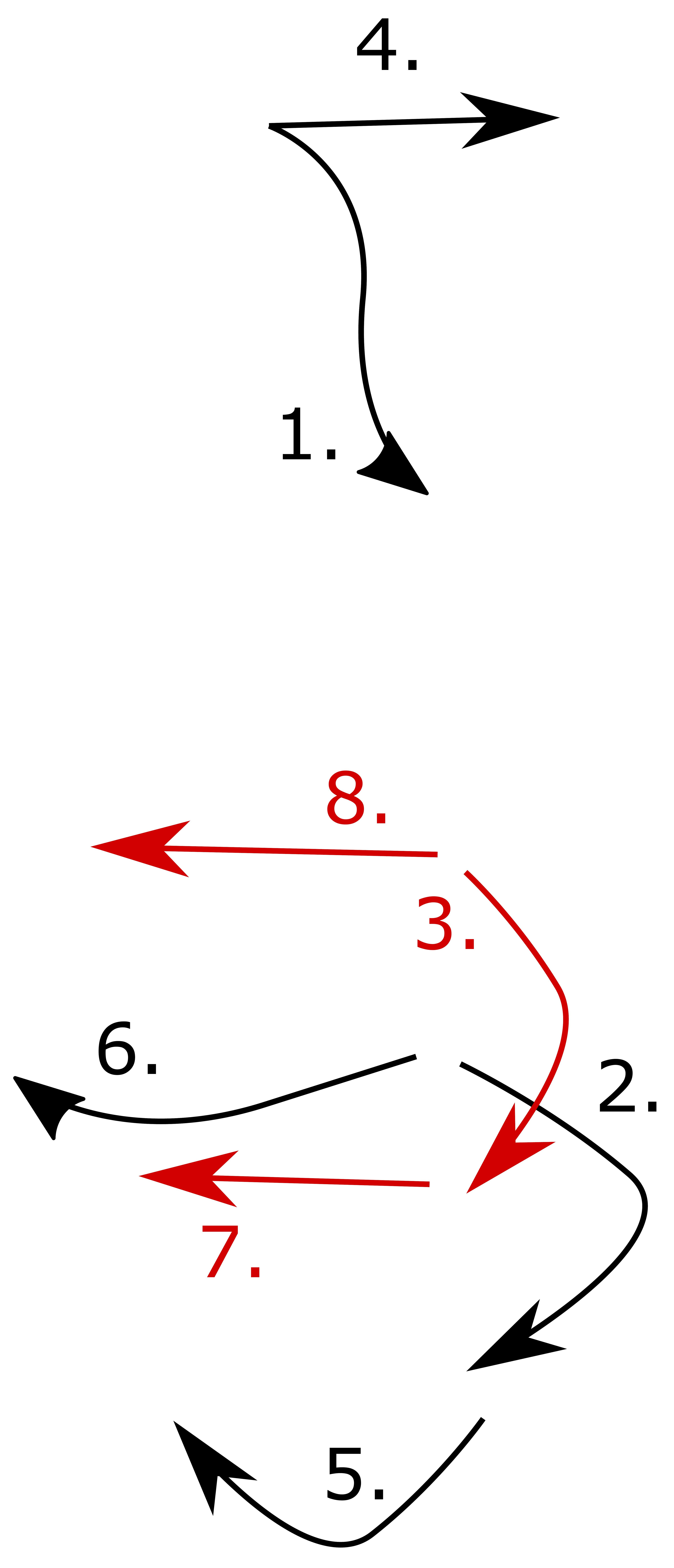

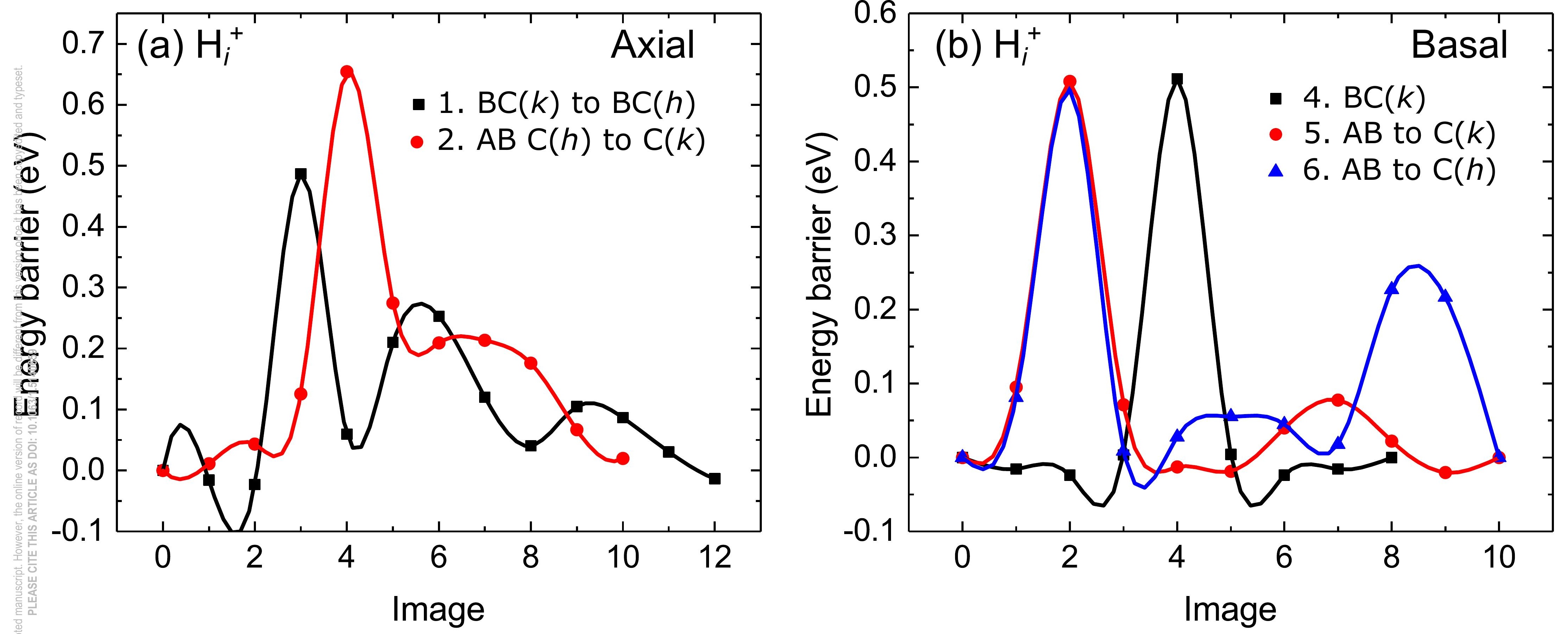

(c) $\mathrm{H}_{i}^{-}$

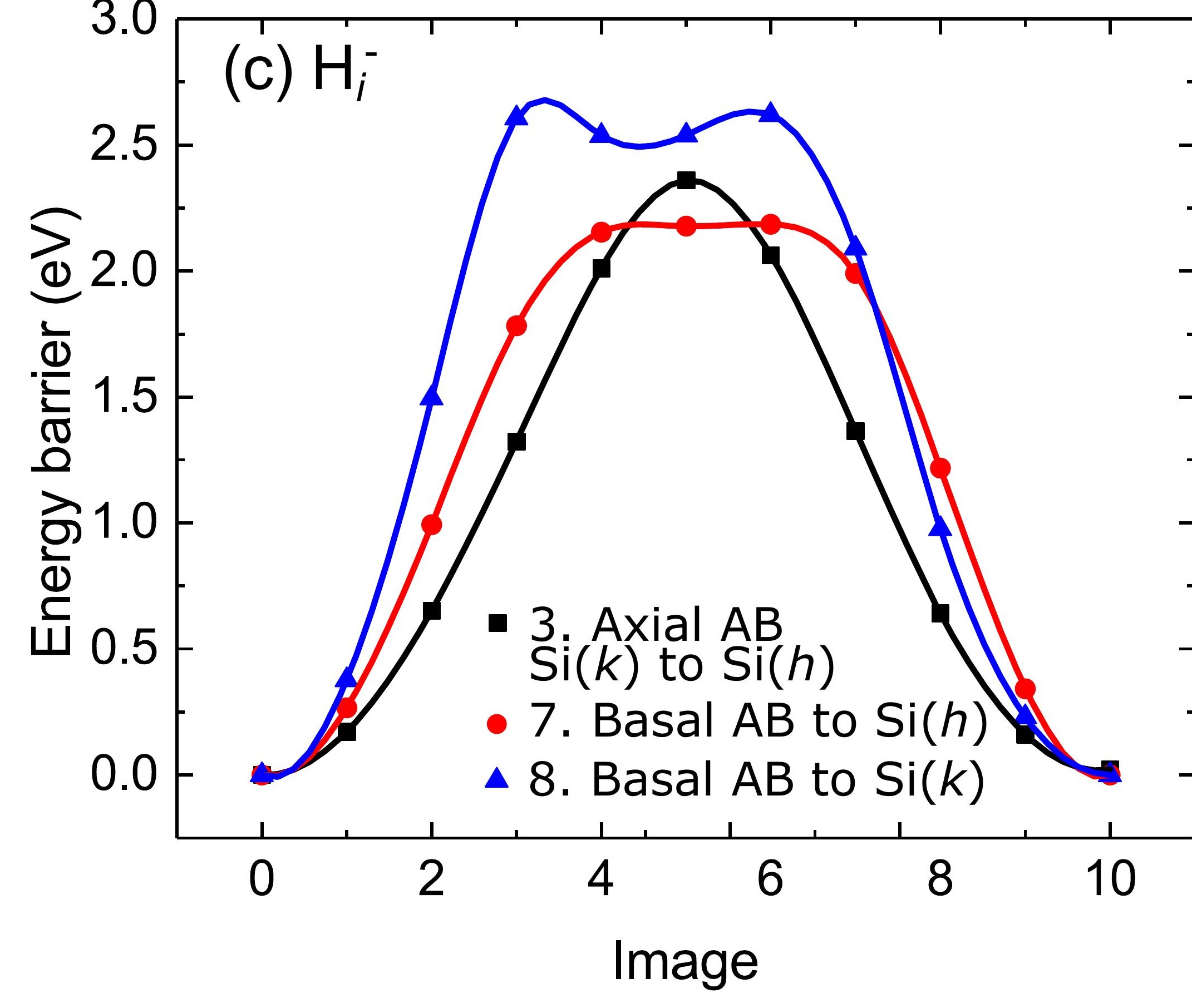




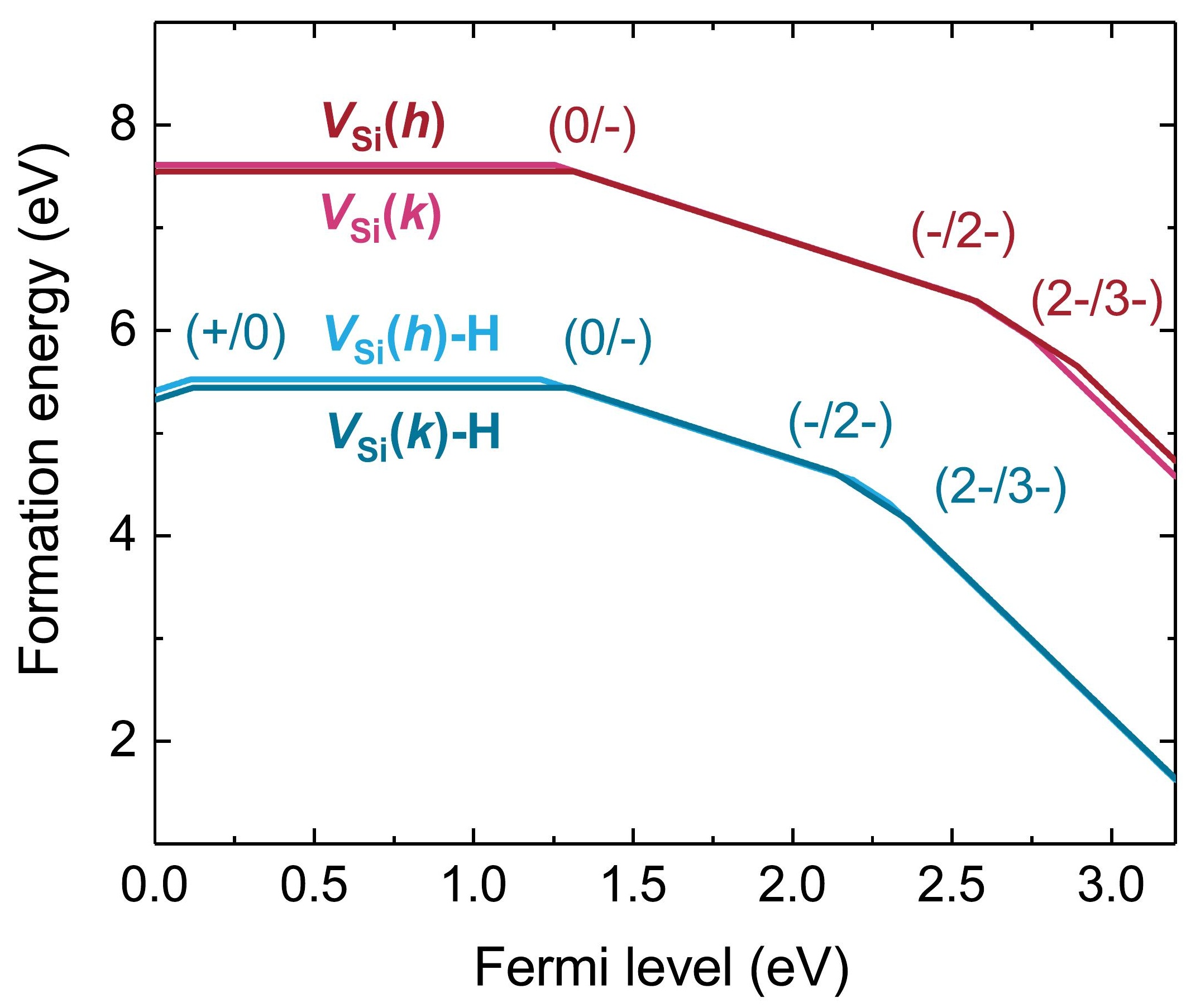




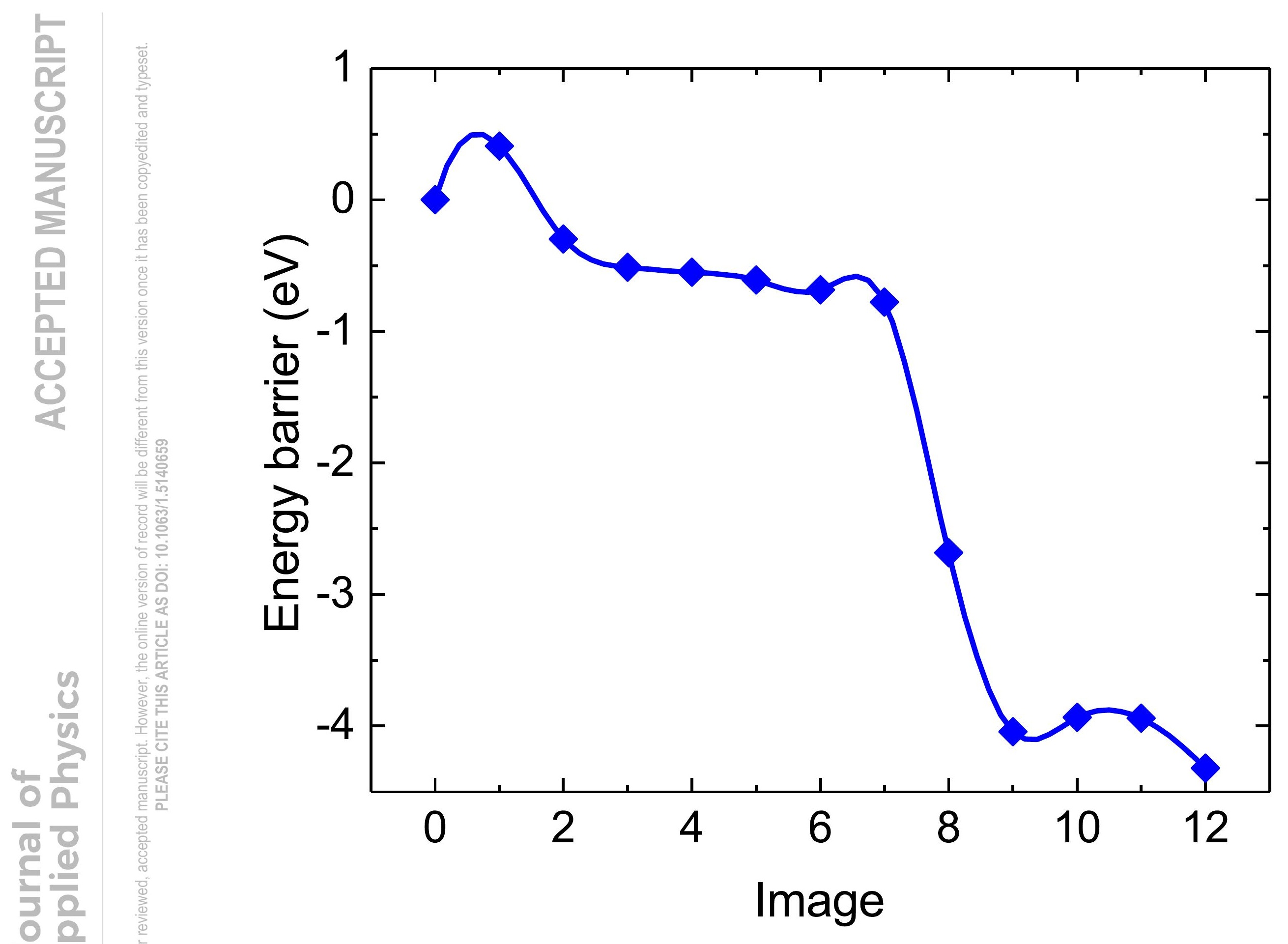


Photon Energy (eV)

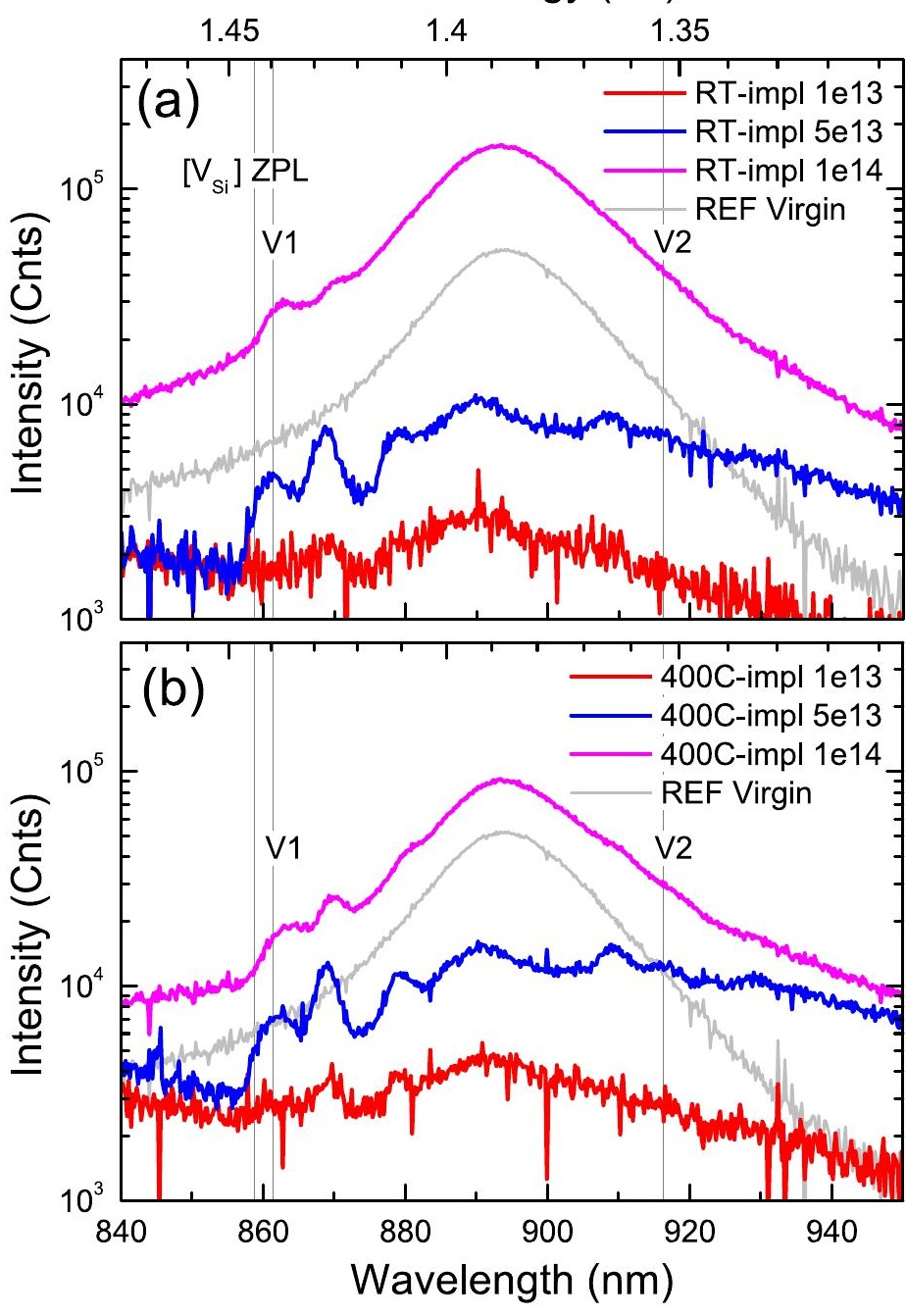



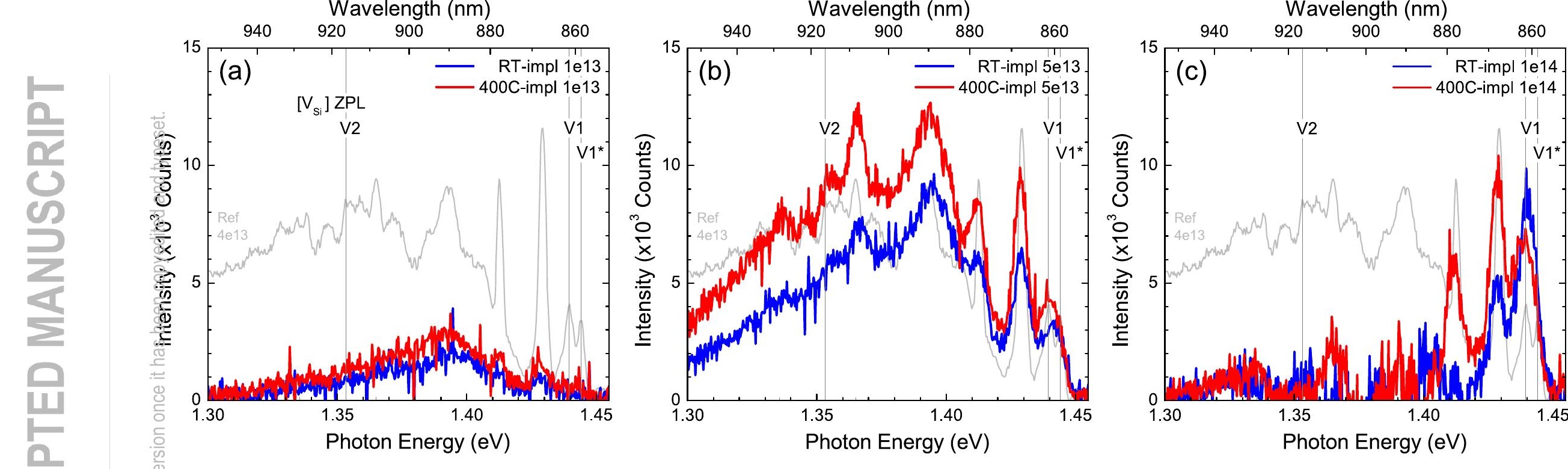